\title{
Justicia constitucional latinoamericana
}

\author{
Algunos desafíos temáticos, esencialmente \\ en materia de derechos humanos
}

Víctor Bazán $n^{1}$

\section{Contenido del trabajo}

Abordaremos aquí algunos retos de la justicia constitucional latinoamericana, que ponen a prueba las posibilidades de fortalecimiento de sus (deseables) roles de defensora de la Constitución, último reducto tuitivo de los derechos humanos en el plano interno y pieza importante de sostén de la institucionalidad democrática en su función de armonizadora de los poderes del Estado.

Nos enfocaremos en determinados desafíos temáticos e incógnitas que surgen en torno a los tribunales, cortes o salas constitucionales y cortes supremas de justicia en el escenario de desarrollo de sus labores jurisdiccionales en el Estado Contemporáneo, que es Estado Constitucional y Convencional.

En ese contexto, hemos previsto: $i$ ) ingresar a la problemática de la utilización de sentencias "atípicas" o "intermedias"; ii) detenernos en las posibilidades de sustentación del control respecto de las omisiones inconstitucionales; iii) argumentar sobre la conveniencia de instrumentar el control de constitucionalidad previo y obligatorio de los instrumentos internacionales o mantenerlo incólume por vía jurisprudencial en caso de que tal modalidad ya estuviera implementada en el texto de la

\footnotetext{
1 Doctor en Ciencias Jurídicas y Sociales. Profesor Titular de las siguientes asignaturas: i) Derecho Constitucional y Derechos Humanos; ii) Derecho Procesal Constitucional, y iii) Derecho Internacional Público, en la Facultad de Derecho, Universidad Católica de Cuyo (San Juan). Profesor Invitado de Posgrado en la Universidad de Buenos Aires (UBA) y en otras universidades argentinas y extranjeras. Autor de numerosos libros y artículos jurídicos publicados en el país y el exterior.
} 
Ley Fundamental correspondiente; iv) resaltar la necesidad de fortalecer los mecanismos internos (también en el plano interamericano) en pro de la exigibilidad y la justiciabilidad de los derechos económicos, sociales y culturales (DESC); y $v$ ) insistir en la indispensable búsqueda de una armónica y eficaz interacción de la jurisdicción constitucional interna con los tribunales internacionales para fortalecer la salvaguardia de los derechos fundamentales, que tiene hoy en el control de convencionalidad uno de sus puntos principales.

Tales cuestiones no son sino sólo algunos de los puntos temáticos que el siglo XXI impone a la justicia constitucional en diversas latitudes de esta región geográfica del continente americano.

\section{Ciertos retos temáticos que enfrenta la justicia constitucional latinoamericana}

Sin pretensiones de taxatividad, nos limitaremos a compartir algunas reflexiones acerca de institutos, instrumentos o herramientas que pueden resultar provechosos para el desarrollo de la eminente labor a cargo de la justicia constitucional en los ámbitos de la defensa y la realización de la Constitución, la protección de los derechos humanos y el cumplimiento de su papel de moderadora de la institucionalidad democrática.

Como aclaración al margen, es preciso puntualizar que en algún caso el cambio de perspectiva y de rumbo jurisprudenciales propuestos deberá acompañarse de una consistente modificación normativa que habilite expresamente la competencia que legitime una innovación en tal sentido.

\section{Sentencias "atípicas" o "intermedias"}

\section{A) Insuficiencia del paradigma 'kelseniano'}

Muy útil en otro momento histórico, el esquema que Kelsen inicialmente diseñara, reducido a distinguir dos únicos tipos de sentencias (estimatorias y desestimatorias) y a considerar al 
Tribunal Constitucional como un "legislador negativo" cuyas resoluciones no podían conllevar más creación de Derecho que la escueta anulación de la ley, desde hace tiempo se vio desbordado por la realidad funcional de los órganos de cierre de la jurisdicción constitucional y los requerimientos del Estado Constitucional ${ }^{2}$.

Se constata, así, que la alternativa constitucionalidad-inconstitucionalidad se revela exigua para cubrir todo el espectro cualitativo de casos que ante aquéllos se presentan, lo que ha propiciado el advenimiento de posiciones jurisdiccionales activistas para modelar variantes sentenciales que permitan a los tribunales, cortes o salas constitucionales y cortes supremas de justicia desempeñar de modo más adecuado el relevante rol que están llamados a cumplir ${ }^{3}$.

En esa lógica, principalmente en Europa (por ejemplo, en los Tribunales Constitucionales de Alemania, Austria, España y la Corte Constitucional de Italia), aunque con irradiaciones hacia la región latinoamericana (v. gr., la Corte Constitucional de Colombia, el Tribunal Constitucional del Perú, la Corte Suprema de Justicia argentina -que desde su por entonces nueva conformación de 2003/2004 buscó reconfigurarse institucionalmente ${ }^{4}$ - y la Sala Constitucional de la Corte Suprema de Justicia de Costa Rica), fue concretándose la construcción

\footnotetext{
2 Cftar. Garrorena Morales, Ángel, “Opacidad y desestimación de la inconstitucionalidad en el fallo de las sentencias interpretativas", en AA.VV., La Democracia Constitucional. Estudios en homenaje al Profesor Francisco Rubio Llorente, Vol. 2, Congreso de los Diputados, Tribunal Constitucional, Universidad Complutense de Madrid, Fundación Ortega y Gasset, Centro de Estudios Políticos y Constitucionales (CEPC), Madrid, 2002, pp. 1844/1845.
}

3 Sobre el punto, ver Bazán, Víctor, por ejemplo en “De jueces subrogantes, casos difíciles y sentencias atípicas", Jurisprudencia Argentina, Abeledo-Perrot, 15 de agosto de 2007, Buenos Aires, pp. 23/33.

4 Al respecto, vid. Bazán, Víctor, ejemplificativamente, en “El Derecho Procesal Constitucional frente al siglo XXI: actualidad y desafíos", en Bazán, Víctor (coord.), Derecho Procesal Constitucional Americano y Europeo, T I, Abeledo-Perrot, Buenos Aires, 2010, pp. 59/86.

Actualmente (2017), la Corte tiene una composición parcialmente diversa. La integran cinco (5) miembros: Ios ministros Lorenzetti, Highton de nolasco, Maqueda, Rosatti y Rosenkrantz (estos dos últimos asumieron en 2016). 
jurisprudencial de "sentencias atípicas o intermedias" que reconocen una génesis primordialmente práctica, como válvula de escape al rígido molde que primigeniamente pensara Kelsen para los tribunales constitucionales.

Es preciso reconocer, no obstante, que no en todas las latitudes de Latinoamérica han sido recibidas estas modalidades sentenciales, observándose en algunas de aquéllas sólo muestras esporádicas que lejos están de dar cuerpo a una doctrina sistemática y uniforme del respectivo órgano de cierre de la justicia constitucional de que se trate.

\section{B) Acercamiento taxonómico}

Acerca de las variantes decisionales en cuestión existen casi tantas clasificaciones como autores se embarcan en intentos taxonómicos a su respecto, lo que demuestra la dificultad de lograr acuerdos absolutos en punto a su sistematización.

Sin embargo, cuando menos existe algún consenso en torno a que la problemática de la interpretación conforme a la Constitución (Verfassungskonforme Auslegung en la terminología alemana) tiene que ver con el nacimiento y la multiplicación de estos instrumentos sentenciales. Según Groppi, la idea se inscribe en el marco de la “'minimización' del impacto de las decisiones de inconstitucionalidad sobre el sistema, a fin de evitar vacíos y de buscar un equilibrio entre la necesidad de eliminar normas inconstitucionales y la de no crear lagunas o discontinuidades que pondrían en duda el carácter de ordenamiento jurídico (...). Con las sentencias interpretativas el juez constitucional hace propia una de las interpretaciones posibles de la disposición censurada, escogiendo la que es conforme (sentencia interpretativa de rechazo) o la contraria (sentencia interpretativa estimatoria) a la Constitución"s.

\footnotetext{
5 Groppi, Tania, “¿Hacia una justicia constitucional 'dúctil'? Tendencias recientes de las relaciones entre Corte Constitucional y jueces comunes en la experiencia italiana”, en Ferrer Mac-Gregor, Eduardo (coord.), Derecho Procesal Constitucional, T० I, $4^{\mathrm{a}}$ ed., Colegio de Secretarios de la Suprema Corte de Justicia de la Nación, Porrúa, México D.F., 2003, p. 355.
} 
Estando las "sentencias interpretativas" vinculadas a la interpretación conforme, ellas parten del presupuesto de la distinción entre disposición y norma, o entre el enunciado normativo y la norma que, por medio de la interpretación constitucional, se desprende del mismo. Ligada a tal faceta de la cuestión, una de las numerosas aproximaciones que se han ensayado sobre las sentencias interpretativas -en este caso, la surgente de la pluma de Rubio Llorente- las entiende como aquellas que emiten un pronunciamiento, no sobre el enunciado de la ley sino de una norma que de él puede deducirse mediante los medios habituales de interpretación ${ }^{6}$.

Ilustrativamente, y dentro de la categorización de las "interpretativas", hay quienes ubican por ejemplo a las sentencias "manipulativas", que a su vez, pueden ser "sustitutivas", "reductoras" o "aditivas". Es, por citar un caso referencial, la posición de Gascón, para quien las primeras sustituyen una interpretación plausible pero inconstitucional del precepto legal impugnado, por otra que claramente no se deduce del mismo, pero que resulta acorde con la Constitución; las "reductoras" suponen precisamente una interpretación restrictiva del ámbito de aplicación del precepto legal impugnado para conformarlo a la Constitución, como producto de lo cual, y luego de la tarea interpretativa, la regla deja de ser aplicable en uno o varios de los supuestos comprendidos en abstracto por el enunciado legal; y las "aditivas", asociadas a la inconstitucionalidad por omisión relativa (problemática que abordaremos más adelante), consisten en una interpretación extensiva del radio de acción del precepto legal objetado, para conformarlo a la Constitución, de resultas de lo cual y tras la interpretación, la regla es aplicable a más supuestos de los comprendidos en abstracto por el enunciado legal.

6 Rubio Llorente, Francisco, "La jurisdicción constitucional como forma de creación del derecho, en La forma del poder. Estudios sobre la Constitución, $2^{a}$ ed., Centro de Estudios Constitucionales, Madrid, 1997, p. 484.

7 Cfr. Gascón, Marina, voz "Interpretación conforme (con la Constitución)", en Carbonell, Miguel (coord.), Diccionario de derecho constitucional, Porrúa y UNAM, México D.F., 2002, p. 318. 
En el necesariamente restringido contexto de este muestreo enunciativo, no podríamos dejar de referir a un enfoque taxonómico que las divide en unilaterales y bilaterales ${ }^{8}$.

Las primeras remedian inmediatamente la inconstitucionalidad modificando la norma considerada anticonstitucional, o sea, el tribunal, corte o sala constitucionales actuarían como legisladores positivos, v. gr., las citadas sentencias interpretativas y las que contienen una declaración de inconstitucionalidad parcial, ya cuantitativa, ya cualitativa.

De su lado, las nombradas en segundo término suponen una interacción entre el órgano de cúpula de la justicia constitucional, el poder legislativo y/o la magistratura ordinaria (incluso podrían denominarse multilaterales si involucran a otro u otros órganos públicos además del congreso o parlamento). Entre aquéllas se pueden incluir, inter alia, a las declaraciones de mera incompatibilidad o de inconstitucionalidad sin nulidad o de inconstitucionalidad simple; las sentencias apelatorias; las sentencias exhortativas y las "sentencias aditivas de principio" o las "sentencias-delegación".

Faceta funcional importante de la cuestión que tratamos es la de la modulación de los efectos de los pronunciamientos por los órganos de justicia constitucional. Mutatis mutandis, y en referencia al contexto español (pero -creemos- con valencia exógena), se ha afirmado que, más allá de purismos dogmáticos, la posibilidad de modular los efectos de la nulidad-lejos de debilitar la eficacia del control de constitucionalidad- en la práctica lo refuerza, ya que permite que el tribunal actúe con mayor libertad al poder cohonestar la declaración de inconstitucionalidad, cuando ésta es necesaria, con la ponderación,

\footnotetext{
8 Aja, Eliseo y González Beilfuss, Markus, “Conclusiones generales”, Aja, Eliseo (ed.), Las tensiones entre el Tribunal Constitucional y el legislador en la Europa actual, Ariel, Barcelona, 1998, pp. 274 y ss.

9 Ver Díaz Revorio, Francisco J., "El control de constitucionalidad de las omisiones legislativas relativas en el derecho comparado europeo", Revista Española de Derecho Constitucional, № 61, Año 21, enero/abril 2001, CEPC, Madrid, pp. 85/86.
} 
no menos necesaria y siempre presente, de las consecuencias prácticas que sobre otros bienes constitucionalmente protegidos puede producir una declaración de nulidad sin modulaciones temporales ${ }^{10}$.

En torno a semejante actividad jurisdiccional modulatoria, pueden contabilizarse enunciativamente las sentencias que retrasan sus efectos para dar tiempo a la intervención del legislador o las que declaran que la ley "todavía no es inconstitucional".

En este punto, es interesante traer a colación las denominadas "sentencias prospectivas", cuyo origen puede ubicarse en la Suprema Corte de Justicia de EE.UU., y que, naturalmente, no tienen eficacia retroactiva, sino que producen efectos pro futuro quedando fijado en las mismas el plazo en que ello ocurrirá. Al respecto, García de Enterría individualiza como punto de partida de tal modalidad sentencial en la jurisprudencia norteamericana a la pronunciada en "Linkletter vs. Walker", de $1965^{11}$, "que rompe conscientemente con el "principle of absolute retroactivity invalidity', por el argumento pragmático de que tal principio aplicado en el caso (una precisión sobre las garantías del proceso penal, especialmente sobre la prueba capaz de justificar un veredicto de culpabilidad) implicaría una grave perturbación de la Administración de la justicia; con ello se pretende "the purpose to be served by the new standards"'12.

\section{C) Advertencia final}

Obviamente, y como en otros ámbitos en cuya superficie la justicia constitucional despliega su labor, en punto a tal abanico de variantes sentenciales deberá ella conducirse con prudencia

\footnotetext{
10 Viver Pi-Sunyer, Carles, en Espín Templado, Eduardo et al., La reforma de la justicia constitucional, Ministerio de Justicia, Centro de Estudios Jurídicos, Thomson - Aranzadi, Navarra, 2006, p. 94.

11381 U.S. 618 (1965).

12 García de Enterría, Eduardo, "La respuesta a las objeciones formuladas contra la justicia constitucional", La Constitución como norma y el Tribunal Constitucional, $3^{\mathrm{a}}$ ed., $2^{\mathrm{a}}$ reimpres., Civitas, Madrid, 1991, p. 181, nota 124.
} 
y mostrarse consciente de sus límites, previsora de las consecuencias de sus pronunciamientos y respetuosa del reparto de competencias y funciones que a los distintos órganos del Estado se les asigna para operar en la respectiva dinámica institucional.

Por otra parte, la importante y polifacética cuestión que tratamos nos tiende el puente hacia el tema que abordaremos a continuación: las posibilidades de sustentación del control sobre las omisiones inconstitucionales en el Estado Constitucional (y Convencional, donde también podrían surgir omisiones inconvencionales).

\section{La inconstitucionalidad por omisión ${ }^{13}$}

\section{A) Liminar}

Recuerda De Otto que la promulgación de una Constitución escrita es prácticamente imprescindible para establecer una norma suprema en el ordenamiento, lo que debe complementarse especificando que la infracción a lo dispuesto en la misma es antijurídica. En cambio, si el ordenamiento no determina tales pautas, los preceptos de ésta serán constitucionales sólo en cuanto están incluidos en ella, pero en realidad no serán ni siquiera normas, dado que una norma que puede ser infringida lícitamente no es una norma ${ }^{14}$. Al respecto, acota que si el ordenamiento preceptúa que es obligatorio acatar la Constitución escrita, "todos" sus preceptos son igualmente obligatorios, sea cual fuere la materia de que se ocupen, y a todos les corresponde por igual la condición de norma suprema ${ }^{15}$ (énfasis del original).

\footnotetext{
13 Sobre la problemática de la inconstitucionalidad por omisión en general, puede consultarse -entre otros trabajos del autor- el libro de Bazán, Víctor: Control de las omisiones inconstitucionales e inconvencionales. Recorrido por el derecho y la jurisprudencia americanos y europeos, nueva ed. ampl. y actualiz., Ediciones Nueva Jurídica y Fundación Konrad Adenauer (Programa Estado de Derecho para Latinoamérica), Bogotá, 2017.

14 De Otto, Ignacio, Derecho Constitucional. Sistema de fuentes, $2^{\mathrm{a}}$ ed., $5^{\mathrm{a}}$ reimpr., Ariel, Barcelona, 1997, pp. 17/18.
}

15 Ibíd., p. 18. 
Embebido de ese espíritu, que enraíza en el Estado Constitucional, se fundamenta y legitima el control de constitucionalidad sobre las omisiones que violenten la Ley Fundamental, en orden a amparar la primacía y el vigor normativo de ésta.

Es interesante la visión de Revenga Sánchez, para quien la fuerza normativa de la Constitución no surge del vacío, y la normatividad constitucional "presenta una dificultad intrínseca que proviene tanto del elevado nivel de abstracción y generalidad de sus prescripciones, como de sus propias fuentes normativas. En el punto de intersección entre la Política y el Derecho -política que se normativiza, y norma que aspira a una regulación de lo político- la Constitución afronta siempre el riesgo de ver socavada su fuerza directriz a manos de actores particularmente poderosos, y con tendencia a presentar resistencia a la vocación limitadora/encauzadora que toda norma, y particularmente la Constitución, conlleva"16 -remarcado añadido-.

Como se precisara hace ya varias décadas en relación con las normas que el legislador ordinario debía dictar para dar plena ejecución a la Constitución, cuando éste se abstiene de estatuir, por ese camino viene a violarla gravemente ${ }^{17}$.

En otros términos, la Constitución puede ser vulnerada no sólo por acción, sino, también, por omisión. Concretamente en este último caso, cuando no se actúa a pesar de la expresa previsión constitucional dirigida a que se lo haga o cuando se regula de modo deficiente plasmando una reglamentación insuficiente o discriminatoria que deja de dotar a algunos de lo que, en igualdad de condiciones o circunstancias, acuerda a otros (tema sobre el que volveremos).

La activación del contralor sobre la inercia inconstitucional persigue entre otros objetivos recomponer el imperio de la Ley

\footnotetext{
16 Revenga Sánchez, Miguel, Presupuestos para la enseñanza del Derecho Constitucional, Serie "Cuadernos del Rectorado", № 22, Universidad Inca Garcilaso de la Vega, Instituto Iberoamericano de Derecho Constitucional (Sección Peruana), Lima, 2010, p. 40.

17 Biscaretti di Ruffia, Paolo, Derecho Constitucional, Colección de Ciencias Sociales, N 48 , Tecnos, trad. de Pablo Lucas Verdú, Madrid, 1965, p. 269.
} 
Fundamental, cuya supremacía habría quedado momentáneamente bloqueada por la inacción del órgano omitente. En línea con ello, cabe recordar que el control de constitucionalidad como noción jurídica es inseparable de la de Constitución como norma suprema de un ordenamiento jurídico dado ${ }^{18}$.

Aunque reiterativo es conveniente recordar que el Estado Contemporáneo es Estado Constitucional, en cuyo marco la Carta Fundamental ocupa un lugar central en el sistema jurídico $^{19}$ (junto a los instrumentos internacionales universales y regionales básicos en materia de derechos humanos con valencia homóloga a ella en aquellos sistemas jurídicos que así lo hayan determinado ${ }^{20}$ ) y ostenta fuerza normativa, lo que

18 Villaverde Menéndez, Ignacio, La inconstitucionalidad por omisión, McGraw-Hill, Madrid, 1997, p. 3.

19 Ver sobre el punto, Bazán, Víctor, "Neoconstitucionalismo e inconstitucionalidad por omisión", Revista Derecho del Estado, № 20, Universidad Externado de Colombia, diciembre de 2007, Bogotá, pp. 121/144.

20 Por citar un caso ejemplificativo, el art. 75, inc. 22, párr. $2^{\circ}$, de la Constitución argentina -de acuerdo con la reforma de 1994- elabora la siguiente nómina de instrumentos internacionales sobre derechos humanos a los que ha acordado jerarquía constitucional: la Declaración Americana de los Derechos y Deberes del Hombre; la Declaración Universal de Derechos Humanos; la Convención Americana sobre Derechos Humanos; el Pacto Internacional de Derechos Económicos, Sociales y Culturales; el Pacto Internacional de Derechos Civiles y Políticos y su Protocolo Facultativo; la Convención sobre la Prevención y la Sanción del Delito de Genocidio; la Convención Internacional sobre la Eliminación de todas las Formas de Discriminación Racial; la Convención sobre la Eliminación de todas las Formas de Discriminación contra la Mujer; la Convención contra la Tortura y otros Tratos o Penas Crueles, Inhumanos o Degradantes; y la Convención sobre los Derechos del Niño (todos estos instrumentos tienen jerarquía constitucional originaria).

A tal registro originario (que en total suma once documentos) se han añadido ex post, con alcurnia homóloga a la Ley Fundamental, la Convención Interamericana sobre Desaparición Forzada de Personas (a la que se ha deparado tal calidad por medio de la Ley N $\mathrm{N}^{0} 24.820$, publicada el 29 de mayo de 1997), la Convención sobre la Imprescriptibilidad de los Crímenes de Guerra y de los Crímenes de Lesa Humanidad (instrumento al que se le ha conferido esa valía mediante la Ley № 25.778, publicada el 3 de septiembre de 2003) y la Convención sobre los Derechos de las Personas con Discapacidad (a la que se le ha otorgado semejante magnitud por la Ley $\mathrm{N}^{0} 27.044$, publicada el 22 de diciembre de 2014) [todos estos instrumentos tienen jerarquía constitucional derivada].

Sobre la cuestión en Argentina, véase de Bazán, Víctor, "La Corte Suprema de Justicia argentina y su rol en la articulación del derecho internacional de los derechos humanos y el 
supone la imperiosa obligación de garantizar la indemnidad de la Constitución, sea que los ataques en su contra se produzcan por acción o por omisión.

\section{B) Variantes tipológicas}

Inmerso en la lógica descripta, y con adscripción al Estado Constitucional, se fundamenta y legitima el control de constitucionalidad ejercitable sobre las omisiones que resultan lesivas de la Ley Fundamental, en tanto la vigencia sociológica de ésta es presupuesto de intangibilidad de los mencionados caracteres vertebrales de supremacía y normatividad.

$\mathrm{Al}$ respecto, es conveniente reenviar a Wessel ${ }^{21}$ cuando de afrontar la tipología de omisiones inconstitucionales se trata. En una simplificación taxonómica extrema (pues profundizar en otras variantes tipológicas de preterición excedería el objeto del presente señalamiento) nos limitamos a indicar que ellas pueden ser: absolutas o totales, cuando directamente media ausencia de la norma que debería regular una determinada situación jurídica fijada constitucionalmente; y relativas o parciales, cuando el legislador, al emitir la norma para cumplir el mandato constitucional, y en equivalencia de condiciones y circunstancias, favorece a ciertos grupos y, sin fundamento objetivo, deja de lado a otros o concede ventajas a unos que no son dispensadas a otros, es decir que, al legislar, lesiona el principio de igualdad con su presupuesto de no discriminación (aunque puede involucrar otros principios

derecho interno", Revista de Derecho Político, № 73, Universidad Nacional de Educación a Distancia (UNED), septiembre/diciembre de 2008, Madrid, pp. 315/373.

En torno al tema en el derecho comparado, ver el mismo autor, por ejemplo, en "Conexiones y tensiones entre el derecho internacional de los derechos humanos y el derecho interno en Latinoamérica", en Velásquez Ramírez, Ricardo y Bobadilla Reyes, Humberto (coords.), Justicia constitucional, derecho supranacional e integración en el derecho latinoamericano, "VIla Convención Latinoamericana de Derecho", Santiago de Chile, 8 a 12 de octubre de 2007, Grijley, Lima, 2007, pp. 269/307.

21 Wessel, Franz, “Die Rechtsprechung des Bundesverfassungsgerichts zur Verfassungsbeschwerde", Deutsches Verwaltungsblatt (DVBI), cuad. 6, 1952, p. 164. 
o valores como el debido proceso) o emite una regulación deficiente gestada por una regla incompleta o normativamente insuficiente.

Avanzando en esa línea argumental, con un punto de toque con la problemática que analizamos, puede incluso plantearse la cuestión vinculada al defecto de pronóstico o de prognosis del legislador, esto es, el que gira en derredor de las reglas que, dictadas para operativizar un mandato constitucional concreto, habrían sufrido desgaste o desfase deviniendo anacrónicas y, consiguientemente, disvaliosas. Ello da lugar al interrogante de si la omisión del legislador en actualizarlas, resultaría idónea para desencadenar la corrección jurisdiccional. La doctrina alemana ha destacado la posibilidad de controlar la omisión o inactividad del legislador en mejorar o corregir tales normas. La preterición no se centraría ya en la ausencia total o parcial de la norma, sino en la falta de adaptación o perfeccionamiento de la existente, como propone Gomes Canotilho' ${ }^{22}$.

\section{C) El radio de acción de la magistratura constitucional}

Con todo, es indispensable al menos bosquejar el perímetro y la superficie con que cuenta la magistratura constitucional para analizar el cuadro de situación que le permita descubrir la presencia de pretericiones inconstitucionales y generar los remedios para superarlas. Tal labor requerirá dosis importantes de prudencia y rigor en orden a sortear el riesgo de deslizarse hacia una trivialización de las declaraciones de inconstitucionalidad al ritmo de la insensatez o el apresuramiento.

En esta dinámica reflexiva con que debe actuar el magistrado constitucional para descifrar si convergen o no los requisitos configurativos de la inconstitucionalidad por omisión, no debería prescindirse de un balance cuidadoso y realista de las

22 Gomes Canotilho, José Joaquim, Direito Constitucional, 6ª ed. rev., Almedina, Coimbra, 1993, p. 1091. 
diversas pautas en juego: normatividad y primacía de la Constitución; connotaciones axiológicas del derecho alegado o de la situación jurídica contraria a la Constitución que la omisión provoca; lapso de tiempo por el que viene manteniéndose la pasividad del órgano deferente; margen de acción (o de inacción) del legislador o de la autoridad pública comprometida; abanico de posibilidades al alcance de la judicatura para disponer la efectivización de una solución material y financieramente posible; $y$, entre otros aspectos, el deber de ejercer cabalmente el control de constitucionalidad.

Semejante ejercicio jurisdiccional supone naturalmente tener siempre presente la obligación de generar una solución equilibrada que ni conlleve a una temeraria invasión de sectores de atribuciones propios de otros poderes estatales, ni obture la actuación judicial si el órgano competente anula arbitrariamente la vigencia de la supremacía constitucional al omitir sine die el cumplimiento de los mandatos constitucionales o, ya en tarea de desarrollo constitucional, excluye injustificada y discriminatoriamente a algunos de lo que concede a otros en igualdad o equivalencia de circunstancias.

\section{D) Breve recorrido por el derecho comparado}

Para ilustrar este acercamiento, realizaremos una visita panorámica por el derecho comparado para recordar que el tema de la inconstitucionalidad por omisión ha sido institucionalizado o gestado por $^{23}$ :

- las Constituciones Nacionales, por ejemplo en Portugal y Hungría, en dominios europeos; en el Brasil, Venezuela

\footnotetext{
23 Un acercamiento a la inconstitucionalidad por omisión en perspectiva iuscomparada puede verse en Bazán, Víctor, "Respuestas normativas y jurisdiccionales frente a las omisiones inconstitucionales: una visión de derecho comparado", en Carbonell, Miguel (coord.), En busca de las normas ausentes. Ensayos sobre la inconstitucionalidad por omisión, $2^{\mathrm{a}}$ ed., IIJ - UNAM, México D.F., 2007, pp. 75/270; y “La inconstitucionalidad por omisión en el derecho comparado, con particular referencia al sistema venezolano", Anuario de Derecho Constitucional Latinoamericano 2006, T I, Fundación Konrad Adenauer, Montevideo, 2006, pp. 475/506.
} 


\section{y Ecuador ${ }^{24}$, ya en Latinoamérica; o en Angola y Timor, en latitudes africana y asiática, respectivamente;}

- la senda legal directa en Costa Rica, por medio de la Ley $\mathrm{N}^{\circ}$ 7.135, de 11 de octubre de 1989; o mediata en cuanto a las omisiones legislativas, en España, donde por conducto de la reforma de la Ley Orgánica del Tribunal Constitucional implementada por la Ley Orgánica No 6/2007, de 24 de mayo, el recurso de amparo en defensa de los derechos fundamentales puede tener ahora por objeto también las omisiones de los órganos judiciales y de las autoridades administrativas, lo que no excluye la posibilidad de un control mediato del poder legislativo ${ }^{25}$. Más recientemente, el 13 de junio de 2011, en República Dominicana se promulgó

24 La actual Constitución del Ecuador, aprobada por el referéndum de 28 de septiembre de 2008, incluye en el cuadro competencial de la Corte Constitucional la atribución de "declarar la inconstitucionalidad en que incurran las instituciones del Estado o autoridades públicas que por omisión inobserven, en forma total o parcial, los mandatos contenidos en normas constitucionales, dentro del plazo establecido en la Constitución o en el plazo considerado razonable por la Corte Constitucional. Si transcurrido el plazo la omisión persiste, la Corte, de manera provisional, expedirá la norma o ejecutará el acto omitido, de acuerdo con la ley" -énfasis añadido- (art. 436, inc. 10).

Es preciso hacer notar que el desborde normativo que algunos autores percibieron en tal cláusula constitucional en punto a que la Corte Constitucional vendría a actuar directamente como un legislador suplente, ha quedado en cierto sentido morigerado, esencialmente respecto de las omisiones normativas absolutas, por la citada LOGJCC, cuyo art. 129.1, dispone: “En el caso de las omisiones normativas absolutas, se concederá al órgano competente un plazo determinado por la Corte Constitucional para la respectiva subsanación. En caso de que no se expida la normatividad en el plazo concedido, la Corte Constitucional formulará por vía jurisprudencial las reglas básicas correspondientes que sean indispensables para garantizar la debida aplicación y acatamiento de las normas constitucionales. Dichas reglas básicas mantendrán su vigencia hasta que se dicten por la Función o institución correspondiente las normas reguladoras de esa materia -bastardillas agregadas-.

25 Sobre el último aserto vertido en el texto (control mediato del poder legislativo), se ha expresado: "El hecho de que se trate de impugnaciones cuyo objeto es de manera inmediata la acción u omisión de los poderes ejecutivo y judicial no excluye la posibilidad de un control mediato del poder legislativo, toda vez que la Sala o la Sección del Tribunal Constitucional que conoce del recurso de amparo puede concluir que la lesión de los derechos fundamentales ocasionada por la acción o la omisión administrativas o judiciales trae en realidad causa de la ley aplicada al caso,..." -cursivas añadidas- (“Los problemas de la omisión legislativa en la jurisprudencia constitucional”, Ponencia del Tribunal Constitucional de España, 
la Ley Orgánica $N^{o}$ 137/11 del Tribunal Constitucional y de los Procedimientos Constitucionales (LOTCPC), que en el art. 47, párr. II, prefigura la posibilidad del dictado de sentencias interpretativas aditivas para conjurar las omisiones legislativas inconstitucionales, entendidas en sentido amplio, como ausencia de previsión legal expresa de lo que constitucionalmente debía haberse previsto;

- las Constituciones locales en países con estructura federal, como Brasil, México y Argentina; y

- el despliegue jurisprudencial de los Tribunales Constitucionales de Alemania y España y la Corte Constitucional de Italia, en Europa; y de la Corte Constitucional de Colombia (por ejemplo, Sentencias Nos. C-073/96, C-543/96, C-540/97, C-080/99, C-956/99, C-427/00, C-1433/00, C-007/01， C-1064/01， C-041/02， C-185/02， C-871/02, C-402/03, C-858/06), el Tribunal Constitucional del Perú (Exptes. $\mathrm{N}^{\text {os. }}$ 2.945-2003-AA/TC, in re “A.A.M.G.", y 054272009-PC/TC, "Asociación Interétnica de Desarrollo de la Selva -AIDESEP-), el hoy extinto Tribunal Constitucional de Bolivia (en la Declaración Constitucional $N^{\circ}$ 06/2000 y las Sentencias Constitucionales 0009/2004 y 0018/2004), la Corte de Constitucionalidad de Guatemala (Expte. No $266-$ 2012, de 14 de febrero de 2013), las Supremas Cortes de Justicia de República Dominicana (in re "Productos Avon S.A.", de 24 de febrero de 1999), México (las Controversias constitucionales 46/2002 de 10 de marzo de 2005 y 14/2005 de 3 de octubre de 2005, que dieron lugar a tres tesis jurisprudenciales relevantes: 9, 10 y 11 de 2006 26 ), y Argentina (v. gr., en los casos "Badaro, Adolfo Valentín

"XIV Conferencia de Tribunales Constitucionales Europeos", Vilna, Lituania, mayo de 2008, www.Irkt.It/conference/Pranesimai/ES-Lituania\%202008.doc).

26 Tituladas: "Principio de división funcional de poderes. Sus características"; "Órganos legislativos. Tipos de facultades o competencias derivadas del principio de división funcional de poderes" y "Omisiones legislativas. Sus tipos"; Semanario Judicial de la Federación y su Gaceta, 9a Época, Pleno, T. XXIII, febrero de 2006, pp. 1533, 1528 y 1527, respectivamente. 
c/ANSeS s/Reajustes varios" $\mathrm{I}^{27}$, de 8 de agosto de 2006, y $\mathrm{II}^{28}$, de 26 de noviembre de 2007, y "Halabi, Ernesto c/P.E.N. - Ley 25.873 - Dto. 1.563/04 s/Amparo Ley 16.986"29, de 24 de febrero de 2009; por enumerar algunos decisorios), en tierras americanas.

\section{E) Epílogo}

Para comenzar a cerrar este señalamiento acudimos a Carrillo, quien asegura que en Europa (aunque -agregamos por nuestra parte- con reflejos hacia el ámbito latinoamericano), la configuración de la justicia constitucional como mecanismo de defensa de la Constitución, ha supuesto una notable innovación en la función jurídica y política de la Ley Fundamental: desde el punto de vista jurídico, porque no hay duda que la Constitución adquiere progresivamente la condición de norma jurídica exigible ante los poderes públicos y los particulares; y desde la óptica política, porque aquélla ordena el sistema político y los Tribunales Constitucionales se convierten en instrumentos de defensa del ordenamiento constitucional ante el legislador y el resto de los poderes del Estado ${ }^{30}$.

La reflexión precedente nos autoriza a reiterar que la discusión en torno a las posibilidades de sustentación jurídicopolítica del contralor de constitucionalidad sobre las omisiones inconstitucionales representa un capítulo más de la tensión constitucionalismo-democracia, judicatura-congreso, tribunal

27 Fallos, 329:3089. El decisorio lleva la firma de los jueces Petracchi, Highton de Nolasco, Fayt, Maqueda, Zaffaroni, Lorenzetti y Argibay.

28 Fallos, 330:4866. Votaron de manera coincidente los ministros Petracchi, Highton de Nolasco, Fayt, Maqueda, Zaffaroni y Lorenzetti.

29 Fallos, 332:111. La mayoría estuvo compuesta por los jueces Lorenzetti, Highton de Nolasco, Maqueda y Zaffaroni; mientras que en disidencia parcial conjunta lo hicieron los ministros Petracchi y Argibay y en disidencia parcial individual lo hizo el doctor Fayt.

30 Carrillo, Marc, "La Jurisdicción Constitucional en Europa: las funciones del Tribunal Constitucional Español y las hipotecas del caso chileno", en Morodo, Raúl y De Vega, Pedro (dirs.), Estudios de Teoría del Estado y Derecho Constitucional en honor de Pablo Lucas Verdú, T II, UNAM y Servicio de Publicaciones de la Facultad de Derecho de la Universidad Complutense de Madrid, Madrid, 2000, p. 1472. 
constitucional-parlamento o, en otras palabras, de la delicada vinculación entre jurisdicción y legislación ${ }^{31}$.

Las relaciones tensionales entre la justicia constitucional y el congreso o parlamento deben reconducirse en términos constructivos y, en el contexto específico de la inercia o la mora legislativas anticonstitucionales, la labor jurisdiccional superadora que al respecto se acometa no debería ser impulsada (ni entendida) en un plano confrontativo o de puja de poder, sino desde la vertiente del diálogo y la colaboración comprometidos institucionalmente en la búsqueda de un equilibrio que, sin soslayar la irrenunciable misión del órgano de cierre de la jurisdicción constitucional de conservar inalterada la vigencia normativa suprema de la Carta Magna, resguarde la estructura del Estado, la división de poderes, la autoridad democrática del legislador y la libertad de configuración política que éste ostenta ${ }^{32}$.

En esa lógica interactiva es tan importante que la magistratura constitucional actúe imbuida de un activismo prudente, como que el congreso o el parlamento asuman la medular importancia de su rol institucional y actúen a la altura de las circunstancias que el Estado Constitucional les impone.

\section{Control de constitucionalidad de los instrumentos internacionales ${ }^{33}$}

\section{A) Control constitucional previo y obligatorio}

Como factores de análisis para una visión integral del problema que nos convoca, no cabría soslayar -inter alia- la

\footnotetext{
31 La frase que cierra este tramo del texto: "la delicada vinculación entre jurisdicción y legislación", es paráfrasis de la apreciación de Zagrebelsky, quien alude a "lo delicado de la relación entre jurisdicción y legislación" (Zagrebelsky, Gustavo, El derecho dúctil. Ley, derechos, justicia, $3^{a}$ ed., Trotta, trad. de Marina Gascón, Madrid, 1999, p. 152).

32 Ver sobre el punto, Bazán, Víctor, Control de las omisiones inconstitucionales e inconvencionales. Recorrido por el derecho y la jurisprudencia americanos y europeos, nueva edición aumentada y actualizada, Ediciones Nueva Jurídica y Programa Estado de Derecho de la Fundación Konrad Adenauer, Bogotá, 2017, passim.

33 Para ampliar sobre el particular, ver el libro de Bazán, Víctor, Jurisdicción constitucional y control de constitucionalidad de los tratados internacionales. Una visión de derecho comparado, Porrúa, México D.F., 2003, passim.
} 
creciente interdependencia de los Estados, la imposibilidad de aislamiento frente a los fenómenos de globalización e integración económica, la necesaria imagen de seriedad y confiabilidad hacia la comunidad internacional sustentada en la garantía de la seguridad jurídica fronteras adentro y la solidificación de la decisión institucional de dar cumplimiento a los compromisos internacionales que acometa el Estado en cuestión.

En esa realidad contextual no nos parece que la temática en estudio recepte una importancia menor o secundaria; tampoco, que sea indiferente que un determinado ordenamiento jurídico diseñe normativamente o habilite jurisprudencialmente un control de constitucionalidad represivo o posterior de los instrumentos internacionales en vigor.

Pensamos que una vez que el documento internacional en cuestión se encuentre en vigor e integrado al ordenamiento jurídico interno, resultaría inconveniente habilitar a su respecto un control de constitucionalidad a posteriori, pues si siguiéramos un razonamiento hipotético, ¿qué sucedería si el órgano jurisdiccional constitucional pertinente concluyera que el mismo es total o parcialmente inconstitucional y, al hilo de tal decisión, se optara por no cumplir sus postulados? Percibimos que semejante alternativa podría coadyuvar al debilitamiento del contenido axiológico y jurídico de la exigencia que se impone a todo Estado de honrar sus compromisos internacionales. Ello tampoco supondría -precisamente- respetar los principios generales del derecho internacional y, ya en particular, las pautas pacta sunt servanda (norma fundamental de todo el derecho de los tratados), cumplimiento de buena fe, interpretación conforme al objeto y fin del tratado e improcedencia de alegar disposiciones de derecho interno para justificar el incumplimiento de los acuerdos internacionales; y, por el contrario, propiciaría el demérito de la seguridad jurídica y el desencadenamiento de la responsabilidad internacional del país en cuestión. 


\section{B) Señalamiento iuscomparado}

De un rápido recorrido por un sector de la preceptiva constitucional latinoamericana: Colombia, Ecuador, Bolivia, Chile, Venezuela y República Dominicana, tomado sólo para graficar la problemática expuesta, surge que -aunque con matices-, en aquél se diagrama por vía de principio un control de constitucionalidad previo o preventivo de los instrumentos internacionales, que puede adoptar las modalidades que a continuación se detallarán.

\section{a) Obligatorio}

Tal tipología se configura, no exenta de matices, por ejemplo en Colombia, Ecuador, Bolivia y República Dominicana.

i) En Colombia, y pese a la solución que por mayoría adoptó la Corte Constitucional (C.C.) en la Sentencia $N^{\circ}$ C-400 de $1998^{34}$ (a favor de su competencia para resolver respecto de demandas de inexequibilidad incoadas contra tratados internacionales perfeccionados con anterioridad a la vigencia de la Constitución de 1991), pareciera que el propio material

\footnotetext{
34 Expediente L.A.T.-108; M.P.: Alejandro Martínez Caballero, respecto de la "Convención de Viena sobre el Derecho de los Tratados entre Estados y Organizaciones Internacionales o entre Organizaciones Internacionales", formalizada en Viena el 21 de marzo de 1986 y de la Ley N 406 de 24 de octubre de 1997 por medio de la cual se aprueba dicha Convención, la Corte Constitucional dejó en claro que abandonaba la doctrina desarrollada en la Sentencia N ${ }^{0}$ C-276 de 1993 (M.P.: Vladimiro Naranjo Mesa) relativa a su inhibición de examinar la constitucionalidad de un tratado internacional perfeccionado; criterio, este último, ya expuesto por la Corte Suprema de Justicia en Sentencia de 6 de junio de 1985 (M.P.: Carlos Medellín Forero). A su vez, con la Sentencia N C-276 de 1993 la Corte Constitucional había corregido el curso tomado mediante la Sentencia N ${ }^{\circ}$ C-027 de 5 de febrero de 1993 (M.P.: Simón Rodríguez Rodríguez), en la que decidió sobre el mérito de las demandas incoadas contra la Ley N 20 de 1974 y contra el Concordato celebrado entre Colombia y la Santa Sede en 1973, algunos de cuyos artículos fueron declarados inexequibles, no obstante que el aludido instrumento internacional había sido objeto de canje de ratificaciones desde el 2 de julio de 1975.

En el marco de la Sentencia N ${ }^{\circ}$ C-400 de 1998, son de muy recomendable lectura el salvamento de voto propiciado por el Mag. José Gregorio Hernández Galindo y sendos salvamentos parciales de voto de los Mags. Hernando Herrera Vergara y Vladimiro Naranjo Mesa.
} 
normativo-constitucional y los antecedentes en que éste se basa no ofrecen mayores dudas sobre la modalidad de control de constitucionalidad de los instrumentos internacionales y de sus leyes aprobatorias concebida por la Asamblea Constituyente y volcada al texto de la Ley Fundamental vigente: previo o preventivo y automático, oficioso u obligatorio.

Ello así, y más allá de las discrepancias léxicas acerca de cuáles pudieran resultar las adjetivaciones lingüística o jurídicamente más puras para caracterizarlo, queda al descubierto la imposibilidad de que la C.C. ejerza el control de constitucionalidad posterior, represivo o correctivo, es decir, articulable sobre el tratado o la ley aprobatoria una vez que aquél ha quedado perfeccionado o, para ser más claros, se patentiza la imposibilidad jurídica de que el instrumento internacional sea invalidado constitucionalmente después de su ratificación.

Hacia tal criterio transporta una hermenéutica armonizante de los artículos constitucionales 241, numeral 10, y 9, inter alia.

Aquél, contiene un precepto especial y específico acerca de la aludida competencia fiscalizatoria de la C.C. sobre los tratados internacionales y las leyes que los aprueben, que determina la ocasión exclusiva en la que "cualquier ciudadano podrá intervenir para defender o impugnar su constitucionalidad", directriz que -partiendo de la advertencia lanzada en el introito del art. 241 en el sentido de que a aquélla se le confía la guarda de la integridad y la supremacía de la Constitución "en los estrictos y precisos términos" de dicha norma- no podría (o no debería) quedar mediatizada en el particular por la aplicación de una cláusula general, como la contenida en el numeral 4 del art. 241, para legitimar el control ex post.

Por su parte, el art. 9 aporta lo suyo en cuanto a que las relaciones exteriores del Estado se fundamentan, entre otros puntos, en el reconocimiento de los principios del derecho internacional aceptados por Colombia, algunos de los cuales no saldrían precisamente indemnes frente a la posibilidad de un control de constitucionalidad posterior del tratado internacional. 
Piénsese, por ejemplo y de conformidad con lo anticipado, en las citadas pautas pacta sunt servanda, buena fe e improcedencia de alegar disposiciones de derecho interno para dejar de cumplir las obligaciones internacionales asumidas.

Nos parece que la línea analítica que esbozamos podría permitir una armonización del carácter intangible del derecho internacional con el respeto por los postulados positivados al respecto en la Constitución colombiana.

En dirección convergente al sentido conclusivo que perfilamos parecieran enderezarse algunas sentencias de la C.C., como la $\mathrm{N}^{\circ}$ C-178, de 25 de abril de 1995 (Expediente $\mathrm{N}^{\circ}$ L.A.T. 041; M.P.: Fabio Morón Díaz), o la N ${ }^{\circ}$ C-1.139, de 30 de agosto de 2000 (Expediente $\mathrm{N}^{\circ}$ L.A.T. 167; M.P.: Vladimiro Naranjo Mesa); como así también la ponencia presentada en forma conjunta por los constituyentes que integraron la Comisión Tercera de la Asamblea Nacional Constituyente, que decantara en la Ley Fundamental de 1991, sin olvidar el Acta N$^{\circ} 1$ emanada de la Subcomisión de Relaciones Internacionales de la mencionada Asamblea.

ii) Ya en lo concerniente a Ecuador, la modalidad fiscalizatoria previa y obligatoria fue establecida en la Constitución de 1998. Ello, cuando se trataba de aquellos instrumentos que requirieran la aprobación del Congreso Nacional, es decir, los enumerados en el entonces artículo 161 constitucional. O sea, que se refirieran a materia territorial o de límites; que establecieran alianzas políticas o militares; que comprometieran al país en acuerdos de integración; que atribuyeran a un organismo internacional o supranacional el ejercicio de competencias derivadas de la Constitución o la ley; que se refirieran a los derechos y deberes fundamentales de las personas y a los derechos colectivos; y que contuvieran el compromiso de expedir, modificar o derogar alguna ley.

Tal competencia se puso a cargo del hoy extinto Tribunal Constitucional. Actualmente, esto es, según el citado texto constitucional vigente luego del referéndum de 28 de septiembre de 2008, el art. 438, inc. $1^{\circ}$, estatuye que la Corte Constitucional 
(que sustituyó a aquel Tribunal) emitirá dictamen previo y vinculante de constitucionalidad respecto de los tratados internacionales, con anterioridad a su ratificación por parte de la Asamblea Nacional.

Desarrollando tal disposición constitucional, la Ley Orgánica de Garantías Jurisdiccionales y Control Constitucional ${ }^{35}$ (LOGJCC) ha determinado en su art. 107 que la Corte Constitucional intervendrá a través de los siguientes tres mecanismos: dictamen sobre la necesidad de aprobación legislativa; control constitucional previo a la aprobación legislativa; y control sobre las resoluciones mediante las que se imparte la aprobación legislativa.

Sin embargo, debe advertirse que el art. 112 , inc. $4^{\circ}$, de la LOGJCC abre la puerta al control de constitucionalidad posterior, ya que estatuye: "Cuando se declara la inconstitucionalidad de un tratado ya ratificado, el Estado deberá denunciar el tratado ante el órgano correspondiente, la orden de promover la renegociación del tratado, o promover la enmienda, reforma o cambio constitucional" -énfasis agregado-.

iii) En su momento, según la reforma constitucional de 1994, en Bolivia la competencia que recaía en el Tribunal Constitucional anterior al Tribunal Constitucional liquidador, hacía presumir que el control de constitucionalidad de tratados y convenios internacionales era facultativo o potestativo.

Sin embargo, debe advertirse que, de acuerdo con la vigente Constitución aprobada por el referéndum de 25 de enero de 2009 (que abrogó la Constitución Política del Estado de 1967 y sus reformas), y con una redacción no del todo nítida, el art. 203, inc. $9^{\circ}$, establece como atribución del actual Tribunal Constitucional Plurinacional (TCP), concebido por la Ley Fundamental hoy en vigor, efectuar el control previo de constitucionalidad en la ratificación de tratados internacionales ${ }^{36}$.

\footnotetext{
35 Publicada en el Segundo Suplemento del Registro Oficial N 52 de 22 de octubre de 2009, derogatoria de la Ley del Control Constitucional, promulgada el 2 de julio de 1997.

36 Debe subrayarse que la Disposición Transitoria Novena determina: "Los tratados internacionales anteriores a la Constitución y que no la contradigan se mantendrán en el
} 
Más aún, el Código Procesal Constitucional (instrumentado por la Ley $\mathrm{N}^{\circ} 254$, de 5 de julio de 2012), estatuye en su art. 106: "El control previo de constitucionalidad de Tratados Internacionales tiene por objeto confrontar el texto de dichos instrumentos con la Constitución Política del Estado, antes de su ratificación, y determinar su constitucionalidad o inconstitucionalidad, total o parcial" -destacado agregado-. Más allá del citado art. 106, dicho Código despliega otras referencias a tal tipología de control previo de tratados internacionales en los arts. 104; 105, inc. $1^{\circ}$; y 107/110, de cuya interacción puede afirmarse que semejante fiscalización reviste carácter de obligatorio.

iv) Por último, ubicamos también en la presente categoría a República Dominicana.

Como vimos, en tal contexto jurídico se promulgó la Ley Orgánica $N^{\circ} 137 / 11$, LOTCPC; la que fue modificada por medio de la Ley $\mathrm{N}^{\circ} 145 / 11$, de 4 de julio de 2011, reformándose -en lo que aquí interesa- su Considerando Decimotercero, para que en adelante se lea como sigue: "Que dentro de los procedimientos constitucionales a ser regulados se encuentra el control preventivo de los tratados internacionales" -énfasis añadido-.

De ello se desprende que República Dominicana se suma a la nómina de Estados que han instrumentado el contralor previo y obligatorio de constitucionalidad de los tratados internacionales por el Tribunal Constitucional (T.C.).

ordenamiento jurídico interno, con rango de ley. En el plazo de dos años desde la elección del nuevo Órgano Ejecutivo, éste denunciará y, en su caso, renegociará los tratados internacionales que sean contrarios a la Constitución".

Por su parte, el art. 410 estipula: "La Constitución es la norma suprema del ordenamiento jurídico boliviano y goza de primacía frente a cualquier otra disposición normativa.

"La aplicación de las normas jurídicas se regirá por la siguiente jerarquía:

$1^{\circ}$ La Constitución.

$2^{\circ}$ Las leyes y los tratados internacionales.

$3^{\circ}$ Los decretos supremos.

$4^{0}$ Las normas departamentales, regionales y municipales.

$5^{\circ}$ Normas de carácter administrativo". 
La ley en cuestión contiene las siguientes consideraciones, que señalamos someramente:

- previo a su aprobación por el Congreso Nacional, el Presidente de la República someterá los tratados internacionales suscriptos al T.C., a fin de que éste ejerza sobre ellos el control previo de constitucionalidad (art. 55);

- en cuanto al plazo, el T.C. decidirá sobre la constitucionalidad o no de los tratados internacionales suscriptos dentro de los treinta (30) días siguientes a su recibo. Al hacerlo, si considerare inconstitucional el tratado en cuestión, indicará sobre cuáles aspectos recae la inconstitucionalidad y las razones en que fundamenta su decisión (art. 56);

- tal determinación del T.C. será vinculante para el Congreso Nacional y el Poder Ejecutivo (art. 57). Por su parte, si el tratado internacional es reputado constitucional, esto impide que, posteriormente, el mismo sea cuestionado por inconstitucional ante el T.C. o cualquier juez o tribunal por los motivos que valoró aquel órgano máximo de la justicia constitucional dominicana (cfr. párrafo al citado art. 57); y

- la decisión del T.C. sobre el control preventivo de los tratados, se publicará por los medios oficiales del propio Tribunal (art. 58).

\section{b) Obligatorio y facultativo}

Ambas posibilidades parecieran convivir en Chile, al menos desde el plano normativo y según los supuestos de que se trate, a partir de la reforma constitucional de 2005.

Allí se habría programado un control previo obligatorio de los tratados referentes a materias que en el derecho interno son objeto de ley orgánica constitucional. En tal sentido, el art. 93.1 de la Constitución establece dentro de las atribuciones del Tribunal Constitucional, la siguiente: "Ejercer el control de constitucionalidad de las leyes que interpreten algún precepto de la Constitución, de las leyes orgánicas constitucionales y de las normas de un tratado que versen sobre materias propias 
de estas últimas, antes de su promulgación" -remarcado agregado-; competencia que figura reproducida en el art. 31.1 de la Ley Orgánica Constitucional del Tribunal Constitucional (LOTC), según el D.F.L. $\mathrm{N}^{\circ} 5$, de 1 de junio de $2010^{37}$, que fija el texto refundido, coordinado y sistematizado de tal ley.

Precisamente, la LOTC, en su art. 48, párr. $1^{\circ}$, prevé: "En el caso del número $1^{\circ}$ del artículo 93 de la Constitución, corresponderá al Presidente de la Cámara de origen enviar al Tribunal los proyectos de las leyes que interpreten algún precepto de la Constitución, de las leyes orgánicas constitucionales y de los tratados que contengan normas sobre materias propias de estas últimas" -sobremarcado añadido-.

A su tiempo, y paralelamente, se habría diseñado una hipótesis de contralor previo facultativo a iniciativa de determinados órganos o autoridades del Estado. Así, el art. 93.3 de la Constitución acuerda al Tribunal la atribución de "resolver las cuestiones sobre constitucionalidad que se susciten durante la tramitación de los proyectos de ley o de reforma constitucional y de los tratados sometidos a la aprobación del Congreso"; prerrogativa trasvasada al art. art. 31.3 de la LOTC.

En la parte final del señalado art. 93, al referirse a la pauta contenida en el número 3 del mismo, la Ley Fundamental chilena establece que "el Tribunal sólo podrá conocer de la materia a requerimiento del Presidente de la República, de cualquiera de las Cámaras o de una cuarta parte de sus miembros en ejercicio, siempre que sea formulado antes de la promulgación de la ley o de la remisión de la comunicación que informa la aprobación del tratado por el Congreso Nacional y, en caso alguno, después de quinto día del despacho del proyecto o de la señalada comunicación" -énfasis agregado-. Añade que deberá resolverlo "dentro del plazo de diez días contado desde que reciba el requerimiento, a menos que decida prorrogarlo hasta por otros diez días por motivos graves y calificados” y que tal

37 Publicado en el Diario Oficial de la Republica de Chile, el 10 de agosto de 2010. 
"requerimiento no suspenderá la tramitación del proyecto; pero la parte impugnada de éste no podrá ser promulgada hasta la expiración del plazo referido, salvo que se trate del proyecto de Ley de Presupuestos o del proyecto relativo a la declaración de guerra propuesta por el Presidente de la República”.

Vale precisar que, de conformidad con la parte final del art. 49, in fine, de la LOTC, "si el Tribunal resuelve que uno o más preceptos de un tratado son inconstitucionales, deberá declararlo así por resolución fundada cuyo texto íntegro se remitirá a la Cámara de origen. La inconstitucionalidad total impedirá que el Presidente de la República ratifique y promulgue el tratado. La inconstitucionalidad parcial facultará al Presidente de la República para decidir si el tratado se ratifica y promulga sin las normas objetadas, en caso de ser ello procedente conforme a las normas del propio tratado y a las normas generales del derecho internacional" -remarcado agregado-.

En este último caso (inconstitucionalidad parcial), se comunicará el acuerdo aprobado por el Congreso Nacional, con el quórum correspondiente, y las normas cuya inconstitucionalidad se haya dispuesto, para que el Presidente de la República decida si hará uso de la facultad señalada en el párrafo anterior (cfr. art. 50, in fine, LOTC).

Por lo demás, la LOTC estipula en su art. 51, párrafo primero, que habiéndose pronunciado el Tribunal sobre la constitucionalidad de las normas de un tratado, o de un proyecto de ley orgánica constitucional o de ley que interprete algún precepto de la Constitución Política, no se admitirá a tramitación en el Tribunal ningún requerimiento para resolver cuestiones sobre constitucionalidad de dichos proyectos o de uno o más de sus preceptos.

Como mensaje telegráfico final, pareciera que no concurren motivos jurídicamente incontrovertibles para sostener semejante bifurcación en cuanto al control preventivo de constitucionalidad: obligatorio para los tratados referidos a asuntos objeto de ley orgánica constitucional, y potestativo para los que no lo 
sean. Es que estos últimos también podrían resultar contrarios a la Constitución y, de ese modo, si se omitiera el control previo, eventualmente tampoco debería habilitarse el control posterior de constitucionalidad, puesto que -entre otras razones- el art. 50.1 de la Constitución, en uno de sus tramos, prescribe: "Las disposiciones de un tratado sólo podrán ser derogadas, modificadas o suspendidas en la forma prevista en los propios tratados o de acuerdo a las normas generales de Derecho Internacional". Pero además, semejante hipótesis de fiscalización constitucional a posteriori también violaría los nombrados principios iusinternacionales fundamentales contenidos en los arts. 26 y 27 y su relación con el art. 31.1, todos de la Convención de Viena sobre el Derecho de los Tratados.

\section{C) El reto concreto que recae en la justicia constitucional}

Consecuentes con lo expresado hasta aquí, nos pronunciamos a favor del control preventivo o a priori de constitucionalidad de los instrumentos internacionales. Incluso, y para evitar potenciales inconvenientes en el despliegue vivencial de los mismos, pensamos que sería aconsejable pautar que dicha fiscalización fuese obligatoria, en orden a prevenir contradicciones o disturbios jurídicos ad intra; coadyuvar al mantenimiento de la coherencia y la lógica del sistema interno de fuentes, y evitar la vinculación jurídica del Estado pertinente en el ámbito internacional sin proceder, previamente, a las adaptaciones normativas correspondientes (por ejemplo, una reforma constitucional) o, en su caso, a desistir de la aprobación del documento internacional o a concretarla con reservas, en la medida en que éste lo permita.

Justamente, el desafío de la justicia constitucional radica en evitar que la praxis jurisprudencial desnaturalice o erosione el sustrato de las disposiciones específicas de las respectivas regulaciones constitucionales que han estatuido una modalidad preventiva o previa de constitucionalidad de los instrumentos internacionales, habilitando vías forzadas o beterodoxas para canalizar el control a posteriori. 


\section{Sobre la efectivización de los derechos económicos, sociales y culturales}

\section{A) Preliminar}

Entre los derechos civiles y políticos y los DESC existe unidad conceptual, equivalencia de entidad jurídica e interrelación y complementación; y de ninguna manera media separación antinómica. En tal sentido, la utilización léxica de la expresión "generaciones de derechos humanos", u otras equivalentes, no puede ni debe afectar aquella unidad conceptual de los derechos, puesto que ellos imbrican en la dignidad humana, obviamente, también unitaria. De ello se sigue -en palabras de García Ramírezque, planteado el carácter integral de los derechos, corresponde afrontar igualmente el carácter integral de su protección ${ }^{38}$.

Al ser unitaria la dignidad humana, la bifurcación de los derechos humanos en "categorías" pretendidamente diversas y estancas, sólo conduce a la creación de falsas dicotomías que poco aportan en favor de la indivisibilidad, la universalidad y la interdependencia de los derechos humanos, sean éstos civiles y políticos o económicos, sociales y culturales. No es un secreto que los enfoques atomizados o fragmentados, como el que subyace a la tesis de las "generaciones de derechos humanos", han dificultado la evolución del derecho internacional de los derechos humanos ${ }^{39}$ en la dimensión fáctica.

Al menos, podríamos convenir en que tal estereotipada fórmula no puede ser aceptada acríticamente, sino que, como alternativa de "mínima", debe ser repensada, verificando si en definitiva es léxica, histórica y jurídicamente correcta o simplemente una creación discursiva arbitraria ${ }^{40}$.

38 García Ramírez, Sergio, "Protección jurisdiccional internacional de los derechos económicos, sociales y culturales", Cuestiones constitucionales, $\mathrm{N}^{0}$ 9, julio/diciembre de 2003, IIJ - UNAM, México D.F., p. 131.

39 Cfr. Cançado Trindade, Antônio A., en el prólogo a la obra de Pinto, Mónica, Temas de derechos humanos, Editores del Puerto, Buenos Aires, 1997, p. II.

40 Rabossi, Eduardo, "Las generaciones de derechos humanos: la teoría y el cliché", Lecciones y Ensayos, Nos. 69/70/71, 1997-98, Facultad de Derecho y Ciencias Sociales, Universidad de Buenos Aires, Abeledo-Perrot, Buenos Aires, pp. 41 y ss., passim. 
Prestigiosa visión autoral formula serias objeciones a la tesis de la escisión generacional de los derechos. En efecto, y sólo por citar algunos ejemplos, Cançado Trindade alude a la "fantasía de las generaciones de derechos" "11; Rabossi destaca que la consecuencia más dañina que tal doctrina genera es que implica y/o brinda un argumento a quienes sostienen que entre los derechos humanos civiles y políticos y los derechos humanos económicos, sociales y culturales existe una diferencia categorial de fondo o una distinción esencial ${ }^{42}$; por su parte, y entre otros cuestionamientos, Pinto enfatiza que la elección de la variable en que se sustenta dicha tesis es "caprichosa" ${ }^{43} \mathrm{y}$ que la consistente doctrina de la universalidad, la interdependencia y la indivisibilidad de los derechos humanos se ve muy "contrariada" con la fórmula de las generaciones de derechos ${ }^{44}$.

Se impone la necesidad de fortalecer los mecanismos internos de exigibilidad y justiciabilidad de los DESC, como paso previo a la articulación de los resortes transnacionales, dado que -como anticipábamos- la jurisdicción internacional es complementaria o coadyuvante de la nacional ${ }^{45}$.

\section{B) Recorrido jurisprudencial}

Descendiendo de tal marco teórico para enfocar la aplicación práctica del desiderátum tuitivo de los DESC, puede verificarse en la jurisprudencia de algunos de los máximos órganos iusconstitucionales latinoamericanos, con mayor o menor grado de profundidad, una interesante actividad en pro de la efectivización de dichos derechos, tal como se expondrá a continuación.

\footnotetext{
41 Así la denomina Cançado Trindade, Antônio A., "Derechos de solidaridad", en Cerdas Cruz, Rodolfo y Nieto Loayza, Rafael (comps.), Estudios Básicos de Derechos Humanos, $\mathrm{T}^{\circ} \mathrm{I}$, Instituto Interamericano de Derechos Humanos, San José de Costa Rica, 1994, p. 64.

42 Rabossi, Eduardo, op. cit., pp. 49/50.

43 Pinto, Mónica, op. cit., p. 56.

44 Ibíd., p. 57.

45 Ver para ampliar, entre otros trabajos de Bazán, Víctor, "Vías de maximización protectiva de los derechos económicos, sociales y culturales", La Ley, T²007-D, Buenos Aires, pp. 1135/1149.
} 


\section{a) Bolivia}

Su hoy desaparecido Tribunal Constitucional (reemplazado -como anunciábamos- por el Tribunal Constitucional liquidador, actualmente suplantado por el TCP) siguió una laudable vertiente jurisprudencial protectoria ${ }^{46}$.

Pueden citarse, en esa dirección, las Sentencias Constitucionales 411/2000-R, de 28 de abril de 2000, que obligó al Estado a proporcionar tratamiento médico a una enferma crónica y a la realización de hemodiálisis a enfermos renales; 433/2000-R, 530/2000-R y 1.052/2001-R, todas sobre tratamientos médicos de personas con enfermedades crónicas; 0026/2003-R, de 8 de enero de 2003, sobre provisión de tratamiento y medicamentos antirretrovirales a personas con VIH-SIDA; o la 1.871/2003-R, de 15 de diciembre de 2003, acerca de la protección que debe dispensarse a la mujer embarazada, respecto de quien, a pesar de su estado de gravidez, se había ordenado su detención preventiva, desconociendo la especial protección que la Constitución Política reconoce a favor de la maternidad.

\section{b) Argentina}

Con una tónica activista la Corte Suprema de Justicia de la Nación, ejemplificativamente, ha proporcionado cobertura tuitiva a:

- el derecho a la salud, reconocido como derecho fundamental, por ejemplo, in r $e^{47}$ "María, Flavia Judith c/Instituto

\footnotetext{
46 Para un acercamiento al escenario actual de Bolivia, vid. Bazán, Víctor, “Los derechos fundamentales (particularmente económicos, sociales y culturales) en el Estado Plurinacional de Bolivia y ciertos desafíos que a su respecto afronta la justicia constitucional", Anuario Iberoamericano de Justicia Constitucional, № 16, enero-diciembre de 2012, CEPC, Madrid, 2012, pp. 21/60.

47 Fallos, 330:4647. Dicha sentencia revocó la decisión que había rechazado la acción de amparo tendiente a obtener la cobertura integral de los gastos para la atención de una persona con discapacidad de naturaleza motora, mental, visceral y sensorial grave, en virtud de existir un reclamo similar en sede administrativa, pues -entre otros argumentos- la Corte consideró en el voto mayoritario que siempre que se amerite el daño grave e irreparable
} 
de Obra Social de la Provincia de Entre Ríos y Estado Provincial", de 30 de octubre de $2007^{48}$.

- los derechos laborales, v. gr., declarando la inconstitucionalidad de algunas normas de la Ley de Riesgos del Trabajo: "Castillo, Ángel Santos c/Cerámica Alberdi S.A.”9, de 7 de septiembre de 2004, y "Aquino, Isacio c/Cargo Servicios Industriales S.A. s/Art. 39 Ley $24.557 " 50$, de 21 de septiembre de 2004; del tope tarifario implementado en la Ley de Contrato de Trabajo para la cuantificación de la indemnización por despido incausado: "Vizzoti, Carlos Alberto c/AMSA S.A. s/Despido" 51 , de 14 septiembre de 2004; o sustentando la estabilidad laboral del empleado público: "Madorrán, Marta Cristina c/Administración Nacional de Aduanas s/Reincorporación" ${ }^{2}$, de 3 de mayo de 2007.

que se causaría remitiendo el examen de la cuestión a los procedimientos ordinarios, los jueces deben habilitar las vías del amparo, ya que la existencia de otras vías procesales que puedan obstar a su procedencia no puede formularse en abstracto sino que depende de la situación concreta a examinar. En síntesis, por mayoría, y al tiempo de dejar sin efecto el pronunciamiento recurrido, ordenó se remitieran los autos al tribunal de origen para que, por quien correspondiera, se dictara un nuevo decisorio con arreglo al criterio que sentaba el Alto Tribunal.

Los posicionamientos en el Tribunal fueron los siguientes: por la mayoría, los jueces Lorenzetti, Fayt y Maqueda; en sendos votos concurrentes, los ministros Highton de Nolasco y Zaffaroni; y, por último, en disidencia conjunta, los doctores Petracchi y Argibay.

48 Reenviamos a Bazán, Víctor, Derecho a la salud y justicia constitucional, Astrea, Buenos Aires, 2013.

49 Fallos, 327:3610. Votaron coincidentemente los ministros Petracchi, Belluscio, Fayt, Boggiano, Maqueda, Zaffaroni y Highton de Nolasco.

50 Fallos, 327:3753. La posición triunfante fue sustentada por los jueces Petracchi y Zaffaroni. A su turno, por su voto se pronunciaron los ministros Belluscio y Maqueda, en concurrencia conjunta, y Highton de Nolasco y Boggiano, en mociones individuales.

51 Fallos, 327:3677. Se expidieron de modo consonante todos los firmantes: ministros Petracchi, Belluscio, Fayt, Boggiano, Maqueda, Zaffaroni y Highton de Nolasco.

52 Fallos, 330:1989. La mayoría quedó configurada por los jueces Lorenzetti, Fayt y Petracchi; en voto concurrente conjunto se pronunciaron los ministros Highton de Nolasco y Maqueda y en concurrencia individual lo hizo la doctora Argibay. 
- la movilidad y la actualización de haberes previsionales: "Sánchez, María del Carmen c/ANSeS s/Reajustes varios" 53 , de 17 de mayo de 2005; las citadas causas "Badaro" I y II ${ }^{54}$; y "Elliff, Alberto c/ANSeS s/Reajustes varios"55, de 11 de agosto de 2009.

- la inaplicabilidad del tope máximo de haberes previsionales: "Aban, Francisca América c/ANSeS" 56 , de 11 de agosto de 2009.

- la protección de la libertad de asociación sindical: "Recurso de hecho deducido por la actora en la causa Asociación Trabajadores del Estado c/Ministerio de Trabajo s/Ley de Asociaciones Sindicales" 57 , de 11 de noviembre de 2008; y "Rossi, Adriana María c/Estado Nacional - Armada Argentina s/Sumarísimo" 58 , de 9 de diciembre de 2009.

- la tutela de los DESC respecto de las personas privadas de su libertad: por ejemplo, en "Méndez, Daniel Roberto s/Recurso de casación"59, de 1 de noviembre de 2011 (que cita en varios párrafos a la conocida sentencia recaída in re "Verbitsky, Horacio" ${ }^{60}$ ), declaró la inconstitucionalidad del

53 Fallos, 328:1602. La mayoría quedó constituida con los ministros Petracchi, Belluscio, Fayt, Highton de Nolasco y Lorenzetti. A su turno, concurrentemente votaron los jueces Zaffaroni y Argibay, de modo conjunto, y Maqueda, individualmente. Por último, en disidencia se expidió el doctor Boggiano.

54 Ver supra, notas 26 y 27 a pie de página.

55 Fallos, 332:1914. Formaron la mayoría los ministros Lorenzetti, Highton de Nolasco, Fayt, Petracchi, Maqueda y Zaffaroni. Concurrentemente se pronunció la jueza Argibay.

56 Fallos, 332:1933. Integraron la mayoría los jueces Lorenzetti, Fayt, Petracchi, Maqueda y Zaffaroni. En disidencia se expidió la ministra Highton de Nolasco.

57 Fallos, 331:2499. Votaron coincidentemente los ministros Lorenzetti, Highton de Nolasco, Fayt, Petracchi, Maqueda y Zaffaroni.

58 Fallos, 332:2715. Firmaron el fallo los ministros Lorenzetti, Highton de Nolasco, Fayt, Petracchi, Maqueda y Zaffaroni. Por su voto se pronunció la jueza Argibay.

59 Fallos, 334:1216. Votaron coincidentemente los ministros Lorenzetti, Highton de Nolasco, Fayt, Petracchi, Maqueda y Zaffaroni.

60 Fallos, 328:1146. La mayoría quedó conformada por los ministros Petracchi, Maqueda, Zaffaroni, Highton de Nolasco y Lorenzetti. Por su parte, en disidencia se expidió el doctor 
art. 121.'c' de la Ley $24.660^{61}$, de ejecución de la pena privativa de la libertad, que dispone que "[1]a retribución del trabajo del interno, deducidos los aportes correspondientes a la seguridad social, se distribuirá simultáneamente en la forma siguiente: [...] c) $25 \%$ para costear los gastos que causare en el establecimiento". Precisó que ello no sólo frustraba y desvirtuaba los propósitos de la ley en la que se encontraba inserto -sustentar el fin de readaptación social del condenado-, sino que colisionaba con enunciados de jerarquía constitucional, siendo deber de los jueces apartarse de tal precepto y dejar de aplicarlo a fin de asegurar la supremacía constitucional, sin que se tratare de apreciar el mérito, la conveniencia o la oportunidad de una norma dictada por el legislador, cayendo la cuestión bajo la jurisdicción de la Corte, dado que al Poder Judicial le competía garantizar la eficacia de los derechos, y evitar que fueran sean vulnerados, como objetivo fundamental y rector a la hora de administrar justicia y decidir las controversias (consid. $6^{\circ}$, párr. $5^{\circ}$ ).

Luego de señalar que la readaptación social del penado resultaba no un mero objetivo de la ejecución de las penas privativas de la libertad, sino el objetivo "superior" de ese sistema, acotó que del texto constitucional y de los tratados internacionales con dicha jerarquía (arts. 18 y 75, inc. 22, de la Constitución Nacional), surgía "que pesa sobre el Estado el deber de custodia de todas las personas que están sometidas a detención preventiva o condena y que dicho deber estatal debe llevarse a cabo con el debido respeto de los derechos fundamentales reconocidos por dichas normas, en el marco de los estándares internacionales" (consid. $3^{\circ}$, párr. $1^{\circ}$ ).

Antes había advertido que no por su elevado emplazamiento, dicho objetivo consentía toda medida por el solo hecho de

Boggiano y, también disidentemente aunque sólo en forma parcial, lo hicieron por separado los jueces Fayt y Argibay.

61 B.0. de 16 de julio de 1996. 
que se la considerase dirigida a su logro, pues no resultaba admisible que, so color de la mentada readaptación, el Estado pusiera la satisfacción -total o parcial- de obligaciones propias en cabeza del interno (id. consid.).

Vale recordar que el art. 18 de la Constitución Nacional señala que las cárceles serán sanas y limpias para resguardo y no para castigo de los detenidos en ellas -cláusula que según la Corte Suprema tiene contenido operativo-, por lo que se impone al Estado, por intermedio de los servicios penitenciarios respectivos, la obligación y la responsabilidad de dar a quienes están cumpliendo una condena o una detención preventiva la adecuada custodia que se manifiesta también en el respeto de sus vidas, salud e integridad física y moral. Agregó el Alto Tribunal que, más aún: "las carencias presupuestarias, aunque dignas de tener en cuenta, no pueden justificar transgresiones" a dichas obligaciones, pues ello "sería tanto como subvertir el Estado de Derecho y dejar de cumplir los principios de la Constitución y los convenios internacionales que comprometen a la Nación frente a la comunidad jurídica internacional, receptados en el texto actual de aquélla" -art. 5.2 de la Convención Americana sobre Derechos Humanos [CADH]- (consid. $3^{\circ}$, párr. $2^{\circ}$ ).

Apoyándose en diversos documentos internacionales con jerarquía constitucional, instrumentos de soft law e inter alia jurisprudencia de la Corte IDH y el Tribunal Europeo de Derechos Humanos, trasuntó la idea de que por la "relación e interacción especial de sujeción" que se establece entre el interno y el Estado (consid. $5^{\circ}$ ), éste no puede dejar de cumplir respecto de aquél sus obligaciones en materia de derechos económicos, sociales y culturales.

- la defensa de la vivienda única y familiar: "Rinaldi, Francisco Augusto y otro c/Guzmán Toledo, Ronal Constante y otra s/Ejecución hipotecaria"62, de 15 de marzo de 2007.

62 Fallos, 330:855. Los alineamientos fueron los siguientes: el voto que encabeza la sentencia correspondió a los ministros Highton de Nolasco y Maqueda; concurrentemente, en 
- Ios DESC en torno a personas en "situación de calle" $y$, vinculado mediatamente al caso anterior, el derecho de acceso a la vivienda digna: la base fáctica del caso "Q. C., S. Y. c/Gobierno de la Ciudad de Buenos Aires s/Amparo"63, resuelto por la Corte Suprema el 24 de abril de 2012, muestra que una mujer en situación de calle -residente en esa ciudad desde 2000- dedujo una acción de amparo para que el Gobierno local la incluyera, junto a su hijo menor que padecía una discapacidad motriz, visual, auditiva y social producida por una encefalopatía crónica, en los programas en materia de vivienda, y le proporcionara alguna alternativa para salir de la grave situación en que se encontraba.

En primera y segunda instancias se admitió la acción, aunque la sentencia de cámara fue revocada por el Superior Tribunal de Justicia local. Contra dicho fallo, la actora planteó recurso extraordinario federal que, denegado, dio origen a la queja. Ésta fue receptada por la Corte Suprema, que hizo lo propio respecto del citado recurso extraordinario, revocando la decisión recurrida.

Vale destacar que la Corte reiteró que el derecho a la "vivienda digna" es un derecho fundamental $\mathrm{y}$, como tal, consagra las obligaciones de hacer a cargo del Estado, con las siguientes características: $i$ ) no son meras declaraciones, sino normas jurídicas operativas con vocación de efectividad (consid. 10 de la mayoría); ii) esa operatividad tiene un carácter derivado, no directo ( ibid., consid. 11); y iii) están sujetas al control de razonabilidad por parte del Poder Judicial (ibíd., consid. 12).

En cuanto a la nombrada operatividad de carácter derivado, añadió que ella significa que, en principio, su implementación requiere de una ley del Congreso o de una decisión del Poder

forma conjunta y coincidiendo con éstos en sus primeros once considerandos, se expidieron los jueces Lorenzetti y Zaffaroni; y, finalmente, la doctora Argibay se pronunció por su voto.

63 Fallos, 335:452. Los alineamientos fueron los siguientes: la moción que encabeza el fallo fue firmada por los ministros Lorenzetti, Highton de Nolasco, Fayt, Maqueda y Zaffaroni; mientras que en sendos votos individuales se pronunciaron los jueces Petracchi y Argibay. 
Ejecutivo que provoque su implementación, pues existe la necesidad de valorar de modo general otros derechos, como por ejemplo la salud, las prestaciones jubilatorias, los salarios, y también los recursos necesarios, originándose una relación compleja entre el titular de la pretensión, el legitimado pasivo directo que es el Estado y el legitimado pasivo indirecto que es el resto de la comunidad, la que en definitiva soporta la carga. En consecuencia, la Corte manifestó no desconocer las facultades que la Constitución le asigna tanto al Poder Ejecutivo como al Poder Legislativo locales, en el ámbito de sus respectivas competencias, para implementar los programas o alternativas destinados a hacer operativo el derecho referido y al hábitat adecuado. Consideró incuestionable que no es función de la jurisdicción determinar qué planes concretos debe desarrollar el gobierno. Determinó, en síntesis, que todo ello significa que las normas que menciona en el fallo no consagran una operatividad directa, en el sentido de que todos los ciudadanos puedan solicitar la provisión de una vivienda por la vía judicial (ibíd., consid. 11).

Asimismo, puntualizó que aquel control de razonabilidad por parte del Poder Judicial supone que, sin perjuicio de las decisiones políticas discrecionales, los poderes del Estado deben atender a las garantías mínimas indispensables para que una persona sea considerada como tal en situaciones de extrema vulnerabilidad (ibid., consid. 17).

En definitiva, la Corte ordenó al Gobierno de la Ciudad de Buenos Aires que: $i$ ) interviniera con los equipos de asistencia social y salud con los que contaba para asegurar que el niño dispusiera de la atención y el cuidado que su estado de discapacidad requería y proveyera a la actora del asesoramiento y la orientación necesarios para la solución de las causas de su problemática habitacional; y ii) garantizara a la actora, aun en forma no definitiva, un alojamiento con condiciones edilicias adecuadas a la patología que presentaba el niño, sin perjuicio de contemplar su inclusión en algún programa de vivienda en curso o futuro para la solución permanente de la situación de excepcional necesidad planteada. 
c) Chile

El 26 de junio del 2008, su Tribunal Constitucional dictó -por mayoría ${ }^{64}$ - una sentencia trascendente en la materia, impulsando una posición que había estado demorándose en la percepción del Tribunal.

Nos referimos al Rol 976, Requerimiento de inaplicabilidad deducido por Silvia Peña Wasaff respecto del artículo 38 ter de la Ley $\mathrm{N}^{\mathrm{O}}$ 18.933, conocida como Ley de ISAPRES (Instituciones de Salud Previsional), en recurso de protección contra Isapre ING Salud S.A., Rol de Ingreso No 4972-2007, de la Corte de Apelaciones de Santiago.

Así, en lo que aquí interesa y poniéndose a tono con la percepción del Comité de Derechos Económicos, Sociales y Culturales de Naciones Unidas ${ }^{65}-\mathrm{ONU}$ - (aunque sin mencionar expresamente a este órgano) en cuanto a la naturaleza jurídica de estos derechos, la índole de las obligaciones de los Estados Parte frente al Pacto Internacional de Derechos Económicos, Sociales y Culturales (PIDESC) y la aplicación de éste en el derecho interno; ha enfatizado que "la amplia mayoría de la doctrina nacional y extranjera reconoce que los derechos sociales, llamados también derechos de prestación o de la segunda generación, son tales y no simples declamaciones o meras expectativas, cuya materialización efectiva quede suspendida hasta que las disponibilidades presupuestarias del Estado puedan llevarlos a la práctica" -remarcado agregado- (consid. vigésimosexto de la posición mayoritaria).

En otras palabras ha subrayado la juridicidad -y con ella, la alegabilidad ante los órganos jurisdiccionales-, de los DESC, precisando que éstos no tienen una naturaleza necesariamente

64 El fallo fue acordado con el voto en contra de los ministros Juan Colombo Campbell, Raúl Bertelsen Repetto y Jorge Correa Sutil, quienes estuvieron por rechazar el requerimiento en todas sus partes.

65 Observación General (OG) No 3, "La índole de las obligaciones de los Estados Partes (par. 1 del art. 2 del Pacto)", 14 de diciembre de 1990; y OG № 9, "La aplicación interna del Pacto", 3 de diciembre de 1998. 
distinta de los derechos civiles o políticos, en lo que constituye un paso importante en la evolución de la doctrina judicial del Tribunal.

Vale destacar que éste receptó el requerimiento con relación a la discriminación por motivo de edad, al estimar que el aumento del valor de los planes y la precaria situación económica de los adultos mayores podía provocar que se viesen obligados a mudarse al sistema público de salud, lo que violaba el derecho a la salud reconocido en la Constitución en cuanto a la libertad de elegir el sistema de salud público o privado al cual afiliarse.

La sentencia que referimos produjo una catarata de recursos en los tribunales de instancia así como de nuevos requerimientos ante el propio Tribunal Constitucional, que en varios pronunciamientos declaró la inaplicabilidad de la norma que posibilitaba el aumento del precio de los planes en función del sexo y la edad del afiliado.

Finalmente, en el Rol 1.348, de 27 de abril de 2010, el Tribunal se pronunció de oficio por la inconstitucionalidad de la norma, lo que implicó su derogación. Asimismo, y como anunciábamos exhortó al legislador para colmar el vacío normativo que generaba semejante declaración de inconstitucionalidad.

\section{d) Colombia}

Son igualmente dignos de destacar ciertos aspectos de la labor de la Corte Constitucional que, en el marco de la acción de tutela, ha realizado una interesante labor hermenéutica sobre el carácter o la incidencia sociales de aquella acción, además de haber empleado con frecuencia la denominada argumentación "por conexidad", para "comunicar" a otros derechos (como el de la salud) el carácter de "fundamentalidad" que poseen intrínsecamente algunos (como el derecho a la vida). Por ejemplo, mutatis mutandis, las Sentencias T-571 de 1992, justamente sobre el derecho a la salud, o T-079 de 2008, en torno al derecho a una vivienda adecuada. 
Tal modalidad de razonamiento se ha aplicado también en el campo del derecho a la seguridad social, por ejemplo, en las Sentencias C-177 de 1998 y SU-1354 de 2000; particularmente en esta última, donde con claridad la asocia al derecho a la subsistencia digna.

Como ha afirmado Osuna Patiño, la Corte Constitucional también ha empleado la argumentación por conexidad en el ámbito de los derechos colectivos, por vía de principio protegibles por la acción popular, aunque les ha dado canalización tuitiva por la acción de tutela (v. gr., la Sentencia SU-1116 de 2001), "cuando la afectación del interés o derecho colectivo vulnera o amenaza 'por conexidad' un derecho 'fundamental del peticionario""66. Por ejemplo, en el derecho a un ambiente sano y su conexión con los derechos a la vida, a la salud (Sentencia SU-116 de 2001), a la integridad física ${ }^{67}$.

No puede omitirse siquiera una mínima alusión a un decisorio trascendente: la Sentencia T-025 de 2004 sobre desplazamiento forzado interno (correspondiente a la Sala $3^{a}$ de Revisión de la Corte Constitucional), que determinó al respecto un "estado de cosas inconstitucional" ante las condiciones de vulnerabilidad extrema en las cuales se encontraba la población desplazada y la omisión reiterada de brindar protección oportuna y efectiva por parte de las distintas autoridades, violándose los derechos a la vida digna, integridad personal, igualdad, petición, trabajo, salud, seguridad social, educación, minimo vital y protección especial a personas de la tercera edad, mujeres cabeza de familia y niños.

No ha sido ésta la única ocasión en que la Corte ha utilizado la categoría de "estado de cosas inconstitucional", pues -al menos hasta donde alcanza nuestra información- también lo ha efectuado en otras materias, dictando "sentencias estructurales"

66 Osuna Patiño, Néstor, "La tutela de derechos por conexidad", en Cepeda, Manuel J. y Montealegre, Eduardo (dirs.), Teoría constitucional y políticas públicas. Bases críticas para una discusión, Universidad Externado de Colombia, Bogotá, 2007, p. 177.

67 Ibíd., pp. 177/178. 
por ejemplo en el campo de la salud (ver, por caso, la Sentencia T-760 de 2008).

En cierto sentido, las "megasentencias" citadas (respectivamente, en los campos del desplazamiento forzado de personas y del derecho a la salud) permiten pensar en cierta metamorfosis que la jurisprudencia de la Corte Constitucional exhibe en cuanto al pasaje de una protección casuística de determinados derechos sociales a la aludida tipología de sentencias "estructurales".

Otro asunto que se plantea como un reto para la Corte Constitucional en el ámbito de protección de DESC, es la búsqueda de alternativas para articular semejante propósito tuitivo con la regla fiscal implementada no hace mucho tiempo en la Constitución o, en palabras oficiales, la "sostenibilidad fiscal" para alcanzar los "fines del Estado Social de Derecho", lo que se basa en el discurso relativo a que la estabilidad macroeconómica es la que hace a aquél "fiscalmente viable".

Es que por medio del Acto Legislativo 3 de 2011, de 1 de julio ${ }^{68}$, se modificó el art. 334 , párr. $1^{\circ}$, de la Constitución Política (entre otras normas) estableciendo que el Estado "intervendrá, por mandato de la ley, en la explotación de los recursos naturales, en el uso del suelo, en la producción, distribución, utilización y consumo de los bienes, y en los servicios públicos y privados, para racionalizar la economía con el fin de conseguir en el plano nacional y territorial, en un marco de sostenibilidad fiscal, el mejoramiento de la calidad de vida de los habitantes, la distribución equitativa de las oportunidades y los beneficios del desarrollo y la preservación de un ambiente sano. Dicho marco de sostenibilidad fiscal deberá fungir como instrumento para alcanzar de manera progresiva los objetivos del Estado Social de Derecho. En cualquier caso el gasto público social será prioritario" (remarcado agregado).

El párr. $4^{\circ}$ de aquella cláusula establece que el "Procurador General de la Nación o uno de los Ministros del Gobierno, una vez proferida la sentencia por cualquiera de las máximas

68 Diario Oficial № 48.117, de dicha fecha. 
corporaciones judiciales, podrán solicitar la apertura de un Incidente de Impacto Fiscal, cuyo trámite será obligatorio. Se oirán las explicaciones de los proponentes sobre las consecuencias de la sentencia en las finanzas públicas, así como el plan concreto para su cumplimiento y se decidirá si procede modular, modificar o diferir los efectos de la misma, con el objeto de evitar alteraciones serias de la sostenibilidad fiscal. En ningún caso se afectará el núcleo esencial de los derechos fundamentales" -énfasis agregado-.

En síntesis, será todo un desafío para la Corte Constitucional conjugar dicho "criterio" ${ }^{69}$ con el resguardo efectivo de derechos sociales fundamentales.

e) Perú

El Tribunal Constitucional muestra algunas imágenes sentenciales enderezadas a la protección de los derechos sociales.

Por ejemplo, en Expte. $\mathrm{N}^{\circ}$ 2.945-2003-AA/TC, in re "A.A.M.G." (Sala Primera). Se ventilaba allí una acción de amparo contra el Estado peruano, representado por el Ministerio de Salud, en el que la peticionante perseguía el otorgamiento de atención médica integral en su condición de paciente con VIH/SIDA, es decir, la provisión constante de medicamentos necesarios para su tratamiento y la realización de exámenes periódicos, así como las pruebas de CD4 y carga viral, ambos a solicitud del médico tratante y/o cuando la necesidad de urgencia lo requiriera. Tal amparo fue acogido sólo parcialmente por la Tercera Sala Civil de la Corte Superior de Justicia de Lima, razón por la cual la impetrante acudió al Tribunal Constitucional por vía de recurso extraordinario.

\footnotetext{
69 Se ha sostenido que con la promulgación del Acto Legislativo 3 de 2011 "termina el tránsito de uno de los más controvertidos proyectos económicos que, aunque no tuvo mayor visibilidad entre el público, seguramente por su alto carácter técnico, sí enfrentó a los partidos políticos, a los economistas y a los constitucionalistas. Esta controversia llevó a que, en la discusión en el Legislativo, la sostenibilidad fiscal pasara de derecho a principio y que, al final, terminara como criterio" (Cfr. la nota periodística "Derechos con sostenibilidad fiscal", El Colombiano, 11 de julio de 2011, Medellín [http://www.elcolombiano.com/BancoConocimiento/D/derechos...]).
} 
La sentencia del Tribunal Constitucional ordenó que se considerara a la recurrente en el grupo de pacientes que recibirían tratamiento integral contra el VIH/SIDA por parte del Ministerio de Salud, lo que incluiría la provisión de medicamentos y análisis correspondientes, según lo dispuesto por los médicos del hospital tratante y bajo su responsabilidad, al tiempo de exhortar a los poderes públicos a que se cumpla lo dispuesto en el art. 8 de la Ley $\mathrm{N}^{\circ}$ 26.626, debiendo considerarse como inversión prioritaria el presupuesto para la ejecución del Plan de Lucha contra el SIDA.

Es interesante la argumentación que este Tribunal elabora analizando los derechos económicos y sociales en general y en particular el derecho a la salud y su relación inseparable con el derecho a la vida para dar cabida al amparo y razonar que, como jueces constitucionales, sin entrar a cuestionar la política de salud per se, era "necesario analizar la actuación del Estado en el presente caso, al haberse alegado la afectación de derechos de la demandante que ponen en riesgo su propia vida. Si bien es cierto que en el caso de países en desarrollo, como el nuestro, resulta difícil exigir una atención y ejecución inmediata de las políticas sociales para la totalidad de la población, este Tribunal reitera que tal justificación es válida sólo cuando se observen concretas acciones del Estado para el logro de resultados; de lo contrario, esta falta de atención devendría en situaciones de inconstitucionalidad por omisión" (énfasis añadido, Fundamento 39).

Convergentemente, agregó que “...los derechos sociales, como es el caso de la salud pública, no representan prestaciones específicas por sí mismas, pues dependen de la disponibilidad de medios con que cuente el Estado, lo que, sin embargo, de ninguna manera puede justificar la inacción prolongada (...), ya que ello devendría en una omisión constitucional" (remarcado agregado, Fundamento 49).

En dirección afín, pueden contabilizarse -inter alia- las sentencias del Tribunal Constitucional recaídas en Expte. 6.5722006, sobre pensión por viudez en caso de unión de becho, y 4.646-2007, relativa al derecho a la educación. 


\section{C) Derechos exigibles}

En síntesis, y luego del recorrido jurisprudencial meramente ilustrativo efectuado, es preciso recalcar que lo ideal sería que el Estado previera y evitara posibles incumplimientos en el campo de los DESC, pero si ellos igualmente se configuraran, los remedios nacionales darían a aquél ocasión de repararlos localmente antes de que se activen en su contra las instancias transnacionales.

En un marco genérico de discusión, creemos que no es posible soslayar la existencia de una directriz axiológicamente relevante que en todo momento debe ser tenida en consideración tanto por las autoridades pertinentes en el ámbito interno cuanto por los órganos competentes en la dimensión internacional en el respectivo desarrollo de sus funciones: los derechos bumanos son la expresión directa de la dignidad de la persona bumana, sean ellos civiles y políticos o económicos, sociales y culturales.

Aprehender tal premisa configuraría un buen punto de partida para superar preconceptos, abandonar concepciones que ven en los DESC ciertos "defectos congénitos" que obstan a catalogarlos como verdaderos "derechos" o a adjudicarles algún "valor jurídico"70, y dejar de lado percepciones que, al mantener que aquéllos no generan obligaciones estatales correlativas, preconizan la "irresponsabilidad" del Estado en caso de incumplimiento de normas nacionales o internacionales que los reconozcan.

Contrariamente, dichos esfuerzos deberán canalizarse constructivamente $\mathrm{y}$, al superar relativismos y escepticismos, convertirse en aportes para crear, modular y repensar técnicas de realización, vías de maximización o mecanismos de garantía

\footnotetext{
70 Ver al respecto, la respuesta que a tales objeciones brinda Courtis, Christian, "Los derechos sociales como derechos", en AA.VV., Los derechos fundamentales, Seminario en Latinoamérica de Teoría Constitucional y Política 2001, Editores del Puerto, Buenos Aires, 2003, pp. 198 y ss.
} 
de los derechos económicos, sociales y culturales que coadyuven definitivamente a ponerlos en acción $n^{71}$.

En esa línea, y más allá de los casos puntuales esquematizados, se impone una profundización de la labor de la jurisdicción constitucional latinoamericana en el ámbito temático relevado y un dinamismo prudente para generar estándares jurisprudenciales sustentables que, sin resultar temerarios ni atentar contra el equilibrio financiero del Estado, coadyuven a la realización de semejantes derechos.

Por lo demás es de hacer notar que, en el plano regional y además de la $\mathrm{CADH}$, numerosos Estados latinoamericanos han ratificado o adherido (según corresponda) al Protocolo de San Salvador, Adicional a tal Convención en Materia de Derechos Económicos, Sociales y Culturales. Así, el Protocolo ha sido ratificado por: Suriname (10 de julio de 1990), Panamá (18 de febrero de 1993), Ecuador (25 de marzo de 1993), Perú (4 de junio de 1995), El Salvador (6 de junio de 1995), Uruguay (2 de abril de 1996), México (16 de abril de 1996), Brasil (21 de agosto de 1996), Paraguay (3 de junio de 1997), Colombia (23 de diciembre de 1997), Costa Rica (16 de noviembre de 1999), Guatemala (5 de octubre de 2000), Argentina (23 de octubre de 2003), Bolivia (5 de octubre de 2006), Nicaragua

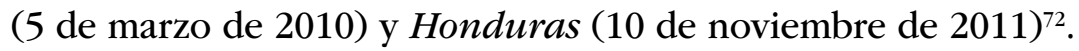

En el ámbito universal, debe resaltarse que uno de los puntos débiles del sistema de protección de DESC siempre ha radicado en la imposibilidad de presentar denuncias individuales ante el Comité de DESC de la ONU. Ello ha tenido comienzo de solución (al menos en su prefiguración normativa) con la adopción el 10 de diciembre de 2008 en Nueva York del Protocolo Adicional al PIDESC, durante la $63^{\mathrm{a}}$ reunión de la Asamblea General de

\footnotetext{
71 Entre otros trabajos de Bazán, Víctor sobre el tema, ver "Los derechos sociales en el derecho interno latinoamericano y el sistema interamericano de protección de los derechos humanos", en el libro de Bazán, Víctor y Jimena Quesada, Luis, Derechos económicos, sociales y culturales, Astrea, Buenos Aires, 2014, pp. 1-167.
}

72 El estado de ratificaciones puede consultarse en: www.cidh.org/Basicos/Basicos4.htm. 
la $\mathrm{ONU}^{73}$. El Protocolo fue firmado por 35 Estados, y entró en vigor el 5 de mayo de 2013 tras alcanzarse la décima ratificación requerida, que fue la de Uruguay, el 3 de febrero de 2013. Es que se había estipulado que el Protocolo cobraría vigencia tres meses después de la fecha de depósito del décimo instrumento de ratificación o adhesión en la Secretaría General de la ONU.

\section{La interacción de la justicia constitucional con los} tribunales internacionales para fortalecer la preservación y el desarrollo de los derechos fundamentales. Control de convencionalidad

\section{A) Prolegómeno}

Nos interesa ahora resaltar el relevante papel que los magistrados constitucionales están llamados a jugar en el Estado Constitucional y Convencional, fundamentalmente en contextos cuyos paisajes jurídicos han sido impactados fuertemente por el derecho internacional de los derechos humanos, como -por citar sólo un ejemplo- el argentino al influjo de la reforma constitucional operada en $1994^{74}$.

La delicada misión que la magistratura constitucional ostenta como último reducto para la defensa y la efectivización de los derechos fundamentales en el ámbito vernáculo deberá ser afrontada y desplegada conociendo y asumiendo la importancia axiológica de las fuentes jurídicas internacionales (instrumentos internacionales sobre derechos humanos, costumbres internacionales consolidadas y principios generales del derecho de las naciones civilizadas), las que habrán de emplearse como guía en la trascendente tarea de interpretación y aplicación de los preceptos de la Ley Fundamental por parte de la jurisdicción constitucional y también, de acuerdo con la valencia que en la propia Constitución se les asigne vis-à-vis el

\footnotetext{
73 Ello, por medio de la Resolución A/RES/63/117.

74 Ver supra en nota 19 a pie de página.
} 
derecho doméstico, como cánones para fiscalizar la adecuación a ellas de las leyes y normas infralegales.

No hacerlo así podría significar -más allá de una objetable despreocupación por la dignidad humana- que el Estado en cuestión incurra en responsabilidad internacional, pues por ejemplo respecto del orden jurídico interamericano, ser parte de la CADH genera tanto un deber de respeto a los derechos humanos como un deber de garantía de éstos (tema sobre el que volveremos).

\section{B) Alusión al control de convencionalidad ${ }^{75}$}

Por su parte, no puede omitirse recordar que en el "Caso Almonacid Arellano y otros vs. Chile", de 26 de septiembre de 2006, la Corte IDH se ha pronunciado en los siguientes términos: "La Corte es consciente que los jueces y tribunales internos están sujetos al imperio de la ley y, por ello, están obligados a aplicar las disposiciones vigentes en el ordenamiento jurídico. Pero cuando un Estado ha ratificado un tratado internacional como la Convención Americana, sus jueces, como parte del aparato del Estado, también están sometidos a ella, lo que les obliga a velar porque los efectos de las disposiciones de la Convención no se vean mermados por la aplicación de leyes contrarias a su objeto y fin, y que desde un inicio carecen de efectos jurídicos. En otras palabras, el Poder Judicial debe ejercer una especie de 'control de convencionalidad' entre las normas jurídicas internas que aplican en los casos concretos y la Convención Americana sobre Derechos Humanos. En esta tarea, el Poder Judicial debe tener en cuenta no solamente el

\footnotetext{
75 Para compulsar diversos aspectos de la cuestión vid. Bazán, Víctor, por ejemplo en: “Corte Interamericana de Derechos Humanos y Cortes Supremas o Tribunales Constitucionales latinoamericanos: el control de convencionalidad y la necesidad de un diálogo interjurisdiccional crítico", Revista Europea de Derechos Fundamentales, № 16, $2^{\circ}$ Semestre de 2010, Fundación Profesor Manuel Broseta e Instituto de Derecho Público Universidad Rey Juan Carlos, Valencia, 2011, pp. 15/44; y “El control de convencionalidad y la necesidad de intensificar un adecuado diálogo jurisprudencial", La Ley. Actualidad, Año LXXV, № 22, Buenos Aires, 1 de febrero de 2011, pp. 1/4.
} 
tratado, sino también la interpretación que del mismo ba becho la Corte Interamericana, intérprete última de la Convención Americana" (remarcado añadido) ${ }^{76}$.

Dicho de otro modo, en tal fallo el Tribunal Interamericano fija a los poderes judiciarios de los Estados (ordinarios y/o constitucionales, según corresponda) la misión de concretar el control de convencionalidad de las normas jurídicas internas que aplican en los casos concretos frente a la $\mathrm{CADH}$, tomando en consideración al efecto no sólo la literalidad de dicho pacto sino la lectura que del mismo ha realizado la Corte, que -como se sabe- es el intérprete último de aquél. Realza, así, la operatividad de la pauta de interpretación conforme a la CADH como estándar hermenéutico a respetar y resguardar por parte de los órganos jurisdiccionales vernáculos.

Aquel Tribunal ha avanzado más aún, estableciendo que tal control de convencionalidad por la magistratura local debe ejercerse incluso de oficio. Así, en el "Caso Trabajadores Cesados del Congreso vs. Perú", puso de manifiesto que "...los órganos del Poder Judicial deben ejercer no sólo un control de constitucionalidad, sino también 'de convencionalidad' ex officio entre las normas internas y la Convención Americana, evidentemente en el marco de sus respectivas competencias y de las regulaciones procesales correspondientes..."77.

Entre otros fundamentos, la aplicación de oficio del control de convencionalidad -que representa una manifestación de la observancia por los jueces locales de la jurisprudencia internacional- puede explicarse -utilizando mutatis mutandis las palabras de Jimena Quesada- "por una correcta puesta en práctica del principio jura novit curia, esto es, cuando el juez interno aplique la jurisprudencia internacional para resolver los

76 Corte IDH, "Caso Almonacid Arellano y otros vs. Chile", Sentencia de Excepciones Preliminares, Fondo, Reparaciones y Costas, 26 de septiembre de 2006, Serie C, № 154, párr. 124.

77 Corte IDH, "Caso Trabajadores Cesados del Congreso (Aguado Alfaro y otros) vs. Perú", Sentencia de Excepciones Preliminares, Fondo, Reparaciones y Costas, 24 de noviembre de 2006, Serie C, N 158, párr. 128. 
casos sobre los que se vea llamado a pronunciarse pese a que las partes procesales no hayan invocado dicha jurisprudencia internacional, que a la postre sea determinante para la resolución de dichos casos [, ya que] la aplicación de las normas internacionales por los jueces nacionales y los demás operadores jurídicos se considera la 'piedra de toque' del cumplimiento efectivo del derecho internacional como tal"78.

Al panorama someramente descripto deben aún agregarse algunos ingredientes significativos.

En esa línea, en el "Caso Cabrera García y Montiel Flores vs. México”, la Corte IDH amplió la plataforma de vinculatoriedad de los sujetos encargados de llevar adelante la fiscalización de coherencia convencional en el derecho interno. Así, precisó que: "Los jueces y órganos vinculados a la administración de justicia en todos los niveles están en la obligación de ejercer ex officio un 'control de convencionalidad' entre las normas internas y la Convención Americana, evidentemente en el marco de sus respectivas competencias y de las regulaciones procesales correspondientes" -cursivas añadidas- (párr. 225) ${ }^{79}$.

Más adelante, el 24 de febrero de 2011, la Corte IDH se pronunció en el "Caso Gelman vs. Uruguay", expandiendo fuertemente las fronteras de operatividad del control de convencionalidad, para colocar a la tutela de los derechos fundamentales como límite a las mayorías en el despliegue de la vida democrática. Sostuvo en tal ocasión que “...particularmente en

78 Jimena Quesada, Luis, "La vinculación del juez a la jurisprudencia internacional”, en Revenga Sánchez, Miguel (coord.), El Poder Judicial, Tirant lo Blanch, Valencia, 2009, p. 542.

Para su afirmación, tal autor se apoya en Conforti, Benedetto (International Law and the Role of Domestic Legal Systems, Dordrecht, Martinus Nijhoff, 1993, p. 9), y pasa luego a agregar: "Cabalmente, cuanto mayor éxito tenga la tarea de difusión de la jurisprudencia internacional entre los operadores jurídicos internos, menos operativo resultará el principio jura novit curia, pues la mayor formación de los abogados comportará una elaboración más cuidada y perfeccionada de sus pretensiones y, por lo tanto, menor margen de discrecionalidad interpretativa en manos de los jueces" ("La vinculación del juez a la jurisprudencia internacional", cit., pp. 542/543 y nota 96 a pie de página).

79 Corte IDH, "Caso Cabrera García y Montiel Flores vs. México", Sentencia de Excepción Preliminar, Fondo, Reparaciones y Costas, 26 de noviembre de 2010, Serie C, № 220. 
casos de graves violaciones a las normas del Derecho Internacional de los Derechos, la protección de los derechos humanos constituye un límite infranqueable a la regla de mayorías, es decir, a la esfera de lo 'susceptible de ser decidido' por parte de las mayorías en instancias democráticas, en las cuales también debe primar un 'control de convencionalidad' (...), que es función y tarea de cualquier autoridad pública y no sólo del Poder Judicial"80 -remarcado agregado-.

En breves palabras, la Corte IDH ha involucrado en la obligación de realizar control de convencionalidad a "cualquier autoridad pública y no sólo del Poder Judicial" -destacado agregado-, lo que supone un mandato con un nivel de generalidad tal que es posible intuir traerá aparejadas ciertas dificultades operativas.

En un nuevo movimiento en la dirección indicada, el Tribunal Interamericano expresó en los Casos "López Mendoza vs. Venezuela" ${ }^{81}$ "Atala Riffo y Niñas vs. Chile" ${ }^{82}$ que, con base en el control de convencionalidad, es necesario que las interpretaciones judiciales y administrativas y las garantías judiciales se apliquen adecuándose a los principios establecidos en su jurisprudencia.

Por último, consideramos de utilidad evocar lo indicado por la Corte IDH en el "Caso de la Masacre de Santo Domingo vs. Colombia” y el "Caso Gelman vs. Uruguay", específicamente en la Resolución de 20 de marzo de 2013, Supervisión de cumplimiento de sentencia ${ }^{83}$ ) en punto a la "obligación propia de todo poder, órgano o autoridad del Estado Parte en la

80 Corte IDH, "Caso Gelman vs. Uruguay", Sentencia de Fondo y Reparaciones, 24 de febrero de 2011, Serie C, № 221, párr. 239.

81 Corte IDH, "Caso López Mendoza vs. Venezuela”, Sentencia de Fondo, Reparaciones y Costas, 1 de septiembre de 2011, Serie C, № 233, párr. 228.

82 Corte IDH, "Caso Atala Riffo y Niñas vs. Chile", Sentencia de Fondo, Reparaciones y Costas, 24 de febrero de 2012, Serie C, № 239, párr. 284.

83 Corte IDH, "Caso de la Masacre de Santo Domingo vs. Colombia", Sentencia de Excepciones Preliminares, Fondo y Reparaciones, 30 de noviembre de 2012, Serie C, N ${ }^{0} 259$, 
Convención, los cuales deben, en el marco de sus respectivas competencias y de las regulaciones procesales correspondientes, controlar que los derechos humanos de las personas sometidas a su jurisdicción sean respetados y garantizados", adquiriendo, así, "sentido el mecanismo convencional, el cual obliga a todos los jueces y órganos judiciales a prevenir potenciales violaciones a derechos humanos, las cuales deben solucionarse a nivel interno teniendo en cuenta las interpretaciones de la Corte Interamericana y, sólo en caso contrario, pueden ser considerados por ésta, en cuyo supuesto ejercerá un control complementario de convencionalidad" -énfasis agregado-.

\section{C) Diálogo interjurisdiccional}

Para finalizar este señalamiento (y dar paso a las observaciones de cierre del trabajo), desde un plano general de análisis corresponde insistir en la exigencia que pesa sobre las autoridades internas competentes en punto a llevar adelante el control de convencionalidad, no obstante lo cual, estamos igualmente persuadidos de la conveniencia de que se desarrolle un diálogo jurisprudencial de los respectivos órganos de cierre de la justicia constitucional de los Estados que conforman el sistema interamericano entre sí y de ellos con la Corte IDH.

En esa dinámica, si bien aquéllos están obligados a receptar los postulados hermenéuticos sentados por el Tribunal Interamericano en sus sentencias y opiniones consultivas: a su vez, éste no puede mostrarse indiferente frente a los valores y principios constitucionales del Estado involucrado, además de ser conveniente que realice un análisis ponderativo de la situación jurídica, social, política e institucional imperante al momento de la violación de derechos humanos que se esgrima en cada caso concreto.

Debe ponerse empeño en instaurar o incrementar una mutua deferencia que permita una convivencia institucional sustentable,

párr. 144; y "Caso Gelman vs. Uruguay", Supervisión de cumplimiento de sentencia, Resolución de 20 de marzo de 2013, párr. 72. 
lo que coadyuvaría a la solidificación del modelo tuitivo de los derechos humanos en nuestra dimensión regional ${ }^{84}$.

En otras palabras, la cuestión ya no puede enfocarse exclusivamente desde una matriz unidireccional desde la Corte IDH hacia los tribunales o cortes constitucionales y cortes supremas (y/o salas constitucionales en el marco de éstas), sino que corresponde hacer foco en una "construcción transnacional y cooperativa de estándares de derechos humanos, con efectos tanto a nivel nacional como regional" ${ }^{\prime 5}$.

Corresponde, por tanto, propiciar una suerte de "fertilización cruzada" (crossfertilization ${ }^{86}$ ) de ambas instancias en la línea de su retroalimentación y plausible reciprocidad de influjos, para enriquecer cuantitativa y cualitativamente la tutela y la realización de los derechos humanos por medio del intercambio y el aprendizaje mutuos.

\section{Epílogo}

1. La lucha de la justicia constitucional latinoamericana por legitimarse social y democráticamente, pugnar por su independencia funcional y económica, superar las carencias presupuestarias, erigirse en eficaz instrumento de defensa y realización de la Constitución y garante final de los derechos

\footnotetext{
84 Remitimos a Bazán, Víctor, "Control de convencionalidad, aperturas dialógicas e influencias jurisdiccionales recíprocas", Revista Europea de Derechos Fundamentales, No 18, $2^{0}$ Semestre 2011, Fundación Profesor Manuel Broseta e Instituto de Derecho Público Universidad Rey Juan Carlos, Valencia, 2012, pp. 63/104.

85 Góngora Mera, Manuel E., “Diálogos jurisprudenciales entre la Corte Interamericana de Derechos Humanos y la Corte Constitucional de Colombia: una visión coevolutiva de la convergencia de estándares sobre derechos de las víctimas", en von Bogdandy, Armin, Ferrer Mac-Gregor, Eduardo y Morales Antoniazzi, Mariela (coords.), La justicia constitucional y su internacionalización. ¿Hacia un 'lus Constitutionale Commune' en América Latina?, T II, IIJ UNAM, Max-Planck-Institut für ausländisches öffentliches Recht und Völkerrecht e Instituto Iberoamericano de Derecho Constitucional, México D.F., 2010, p. 429.

86 Utilizamos tal término a modo ilustrativo y tomándolo mutatis mutandis de lo explicado por De Vergottini, Giuseppe, Oltre il dialogo tra le Corti. Giudici, diritto straniero, comparazione, Il Mulino, Bologna, 2010, p. 20 y notas a pie de página 10, 11 y 12.
} 
humanos en los correspondientes ámbitos internos; son -en general- problemáticas comunes que recorren las respectivas parcelas donde actúan los órganos de la magistratura constitucional pertinente en distintas latitudes de dicho contexto jurídico regional ${ }^{87}$.

El abastecimiento de tales objetivos en el marco del Estado Constitucional, exige una justicia constitucional sea valiente, fuerte, activa e independiente; pero simultáneamente, prudente, equilibrada, consciente de sus límites y respetuosa de la autoridad democrática del legislador.

2. La utilización mesurada de sentencias "atípicas" o "intermedias", que pueden resultar provechosas en la dinámica del modelo constitucional; la incursión en espacios incómodos del control de constitucionalidad como el de la fiscalización de las pretericiones inconstitucionales; el mantenimiento del esquema de contralor de constitucionalidad previo y obligatorio de los instrumentos internacionales (si así viniera estatuido en las respectivas Constituciones); el afianzamiento de los mecanismos internos de exigibilidad y justiciabilidad de los derechos económicos, sociales y culturales; y la búsqueda de una madura y eficaz interacción de la jurisdicción constitucional interna con la Corte IDH para fortalecer la salvaguardia de los derechos fundamentales; no son sino algunos de los desafíos temáticos que figuran en una agenda imaginaria que el siglo XXI impone a la justicia constitucional y al propio Estado Constitucional en Latinoamérica.

3. Un seguimiento de las experiencias normativas (constitucionales o infraconstitucionales) y jurisprudenciales europeas y latinoamericanas (éstas por medio de las citadas modalidades sentenciales "atípicas" o "intermedias"), deja al descubierto el

87 Un acercamiento al tema puede compulsarse en Bazán, Víctor, “Algunos problemas y desafíos actuales de la jurisdicción constitucional en Iberoamérica”, Anuario de Derecho Constitucional Latinoamericano 2007, T I, Fundación Konrad Adenauer, Montevideo, 2007, pp. $37 / 61$. 
paulatino interés por institucionalizar o aplicar pretorianamente diversos mecanismos para superar o corregir las omisiones inconstitucionales. Al menos, se fortalece la idea de que la doctrina de la inconstitucionalidad por omisión tiene algo que ofrecer a favor de la fluidez del tránsito de la supremacía constitucional, la vigencia real de los derechos y la consolidación del Estado Constitucional.

4. Las fricciones entre el congreso y el tribunal, corte o sala constitucionales o el poder judicial (de acuerdo con las respectivas adscripciones a los diversos sistemas de contralor de constitucionalidad) deben recanalizarse en términos de diálogo y convivencia institucional sensatos y no ser concebidas desde un prisma confrontativo o de lucha de poder. Ello, en el marco de una deseable dinámica armónica en la que, sin que la magistratura constitucional abdique de su insoslayable tarea de preservar la vigencia normativa suprema de la Constitución, al mismo tiempo se muestre respetuosa de la división de poderes y la autoridad democrática del legislador.

5. Si bien explorar la doctrina de la inconstitucionalidad por omisión significa ingresar a terrenos inhóspitos del control de constitucionalidad, ya que enlaza con complejos problemas como los de la eficacia y la aplicabilidad de las normas constitucionales y toca puntos conflictivos al procurar corregir inercias de las autoridades competentes que pueden sentirse invadidas en espacios que consideran de su exclusiva discrecionalidad o limitadas antidemocráticamente; el esfuerzo vale la pena. Así, el control sobre las omisiones inconstitucionales supone un mecanismo no desdeñable para sumar en el intento de aproximar los extremos de la brecha erigida entre el discurso normológico y las concreciones pragmáticas de los contenidos de la Ley Fundamental.

6. En un contexto marcado por el crecimiento de la circulación de reglas iusinternacionales y la profundización de la interrelación del derecho internacional de los derechos humanos 
y el derecho interno, adquiere realce cualitativo la realización ad intra por la magistratura jurisdiccional (y otras autoridades públicas) del control de compatibilidad convencional de la normativa doméstica subconstitucional y constitucional vis-à-vis el compacto de reglas y principios que conforman la estructura literal de la $\mathrm{CADH}$ (y de los demás instrumentos integrantes del corpus juris interamericano) y los patrones valorativos que viene forjando la Corte IDH en su labor interpretativa.

Pero ello no debe darse en el contexto de una estricta y exclusiva lógica unidireccional desde la Corte IDH hacia las jurisdicciones nacionales, sino que es preciso generar las condiciones para profundizar un diálogo jurisprudencial entre ambos órdenes de tribunales concernidos: interamericano e internos.

7. En la senda argumental que hemos transitado, que exhibe una dinámica interactiva de las fuentes jurídicas internas e internacionales, no debe perderse de vista que la Constitución, con el vigor normativo que le es inherente, y los instrumentos internacionales sobre derechos humanos, como las disposiciones contenidas -v. gr.- en la $\mathrm{CADH}$ y los patrones hermenéuticos que a su respecto modela la Corte IDH, componen un cuerpo jurídico que orienta su vigencia hacia un idéntico sustrato axiológico: la protección y la realización de los derechos bumanos, que son reflejo directo de la dignidad de la persona.

8. Para finalizar, y en una perspectiva general de discusión, puede constatarse que las bases jurídicas, políticas y axiológicas mínimas de sustentación de un cabal Estado Constitucional, son $^{88}$ : una Constitución suprema y con fuerza normativa, al igual que los instrumentos internacionales básicos en materia de derechos humanos; un sistema democrático no declamado sino real; el goce y el ejercicio efectivos de los derechos bumanos, porque -como afirma Ferrajoli- el progreso de la democracia se

88 Sobre el particular, vid. la monografía de Bazán, Víctor, Estado de Derecho: Perfiles y exigencias actuales, Cuadernos Democráticos № 1, Fundación Konrad Adenauer Ecuador, Quito, 2009. 
mide por la expansión y la justiciabilidad de los derechos ${ }^{89} ; \mathrm{y}$, entre otros elementos, una justicia constitucional que asegure la normatividad y la primacía constitucionales y el respeto y la realización de aquellos derechos sin superfluas distinciones categoriales, esto es, con prescindencia de que sean civiles y políticos o económicos, sociales y culturales ${ }^{90}$.

${ }^{89}$ Ferrajoli, Luigi, Derecho y razón. Teoría del garantismo penal, $2^{a}$ ed., Trotta, trad. de Perfecto Andrés Ibáñez y otros, Madrid, 1997, p. 918.

90 Ver Bazán, Víctor, "La judicialización de los derechos económicos, sociales y culturales", en Bazán, Víctor (dir.), La judicialización de los derechos humanos, Asociación Argentina de Derecho Internacional (Sección Derechos Humanos), Ediciones Legales, Lima, 2009, pp. 257/300. 